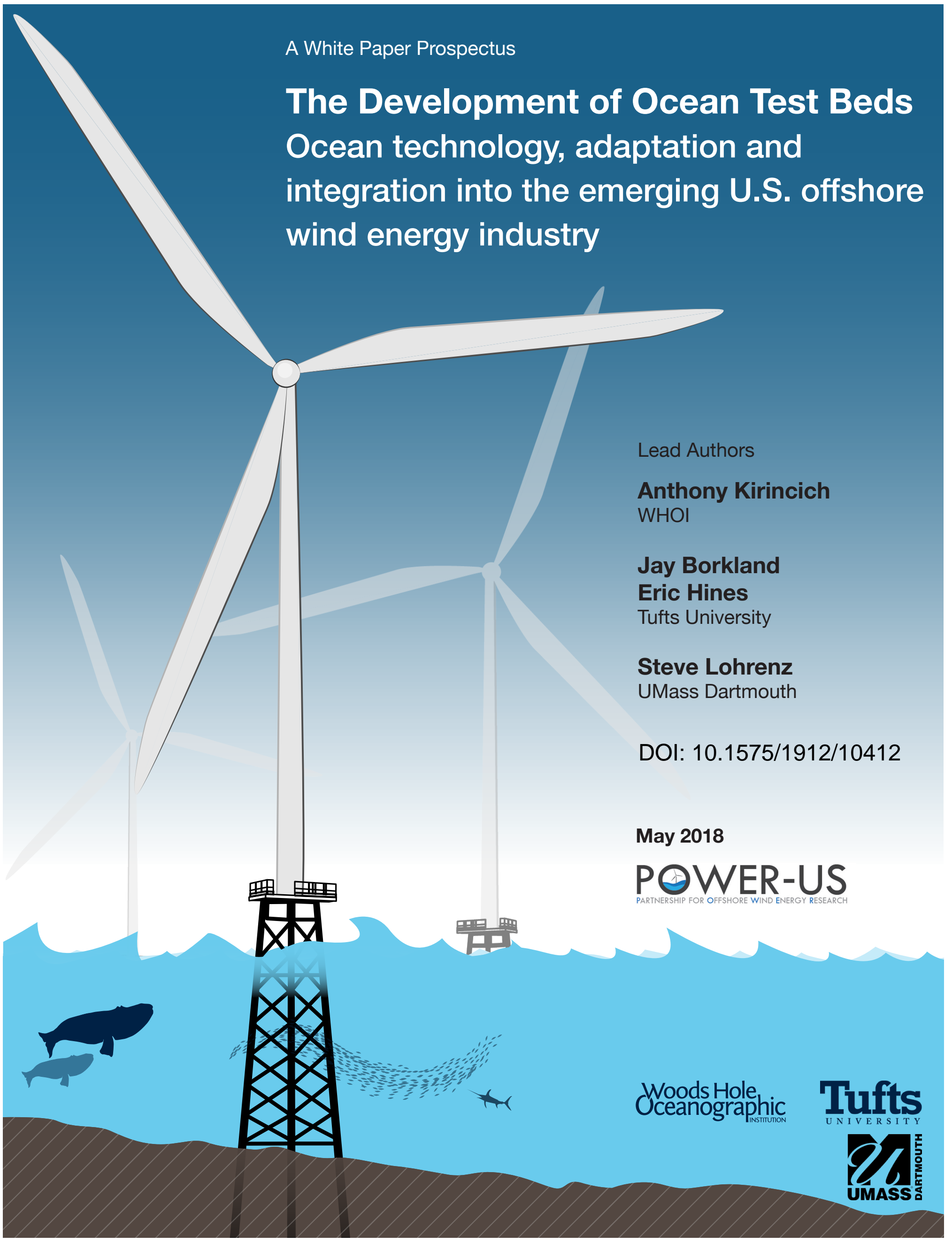


A White Paper Prospectus:

\title{
The Development of Ocean Test Beds for Ocean Technology Adaptation and Integration into the Emerging U.S. Offshore Wind Energy Industry
}

\author{
Lead Authors: \\ Anthony Kirincich (WHOI) \\ Jay Borkland and Eric Hines (Tufts) \\ Steve Lohrenz (UMass Dartmouth)
}

\section{Executive Summary}

The landscape of applied ocean technology is rapidly changing with forces of innovation emerging from basic ocean science research methodologies as well as onshore high tech sectors. There is a critical need for ocean-related industries to continue to modernize via the adoption of state-of-the-art practices to advance rapidly changing industry objectives, maintain competitiveness, and be careful stewards of the ocean as a common resource. These objectives are of national importance for the dynamic ocean energy sector, and a mechanism by which new and promising technologies can be validated and adopted in an open and benchmarked process is needed. POWER-US seeks to develop Ocean Test Beds as research and development infrastructure capable of driving innovative observations, modeling, and monitoring of the physical, biological, and use characteristics present in offshore wind energy installation areas.

The Industry Need: Throughout the second half of the last century, ocean technology advancements ushered in new ocean-related industries and ocean advancements that changed the course of history. Remote and deep water oil and gas exploration and extraction methods, bottom survey methods, global shipping route optimization, ocean storm and weather forecasting, etc. have enabled substantial economic gains. That much of ocean science and engineering today continues to rely on technologies developed in the last century is a testament to the robust nature of our previous development efforts. However, more recent technological innovations in environmental sensing, computing, and automation offer the potential to further revolutionize both existing ocean-related industries such as: energy, mining, transportation and shipping, global trade, adaptation and resiliency, defense and security, salvage, and ocean exploration as well as newly emerging ocean uses.

One clear example of the need for rapid adoption of new technology is in the area of offshore wind energy production. As a new energy industry in the U.S., offshore wind shows tremendous potential as a component of the nation's energy future portfolio. However, solid scientific data on the design characteristics as well as consensus on the interactions of a wind farm with the marine environment are critical to reduce risk, advance public acceptance, and evolve the regulatory process. Coupling this with the unique conditions present over the U.S. outer continental shelf in areas slated for development, an acute need exists for creating the physical and organizational infrastructure to rapidly move innovations in site characterization through systematic validation and into industry best practices and/or regulatory requirements. This process requires an open and evolving infrastructure that allows benchmarked data sets to test and evaluate sensors, improved systems modeling, and analysis by neutral, disinterested parties. 
In the current era, a program of research through which ocean technology can be applied, vetted, and validated is needed in order to advance the adaptation of new technologies and realize their potential for both this and future emerging ocean uses.

The Role of Science: Applied to Offshore Wind Energy as an industry, Ocean Test Beds (OTBs), as innovation and testing centers, would enable the advanced sensing of the sub-bottom, ocean, and atmosphere as well as numerical simulation techniques being made within basic science research to be transitioned into use by the offshore wind energy industry. Concept areas such as the operational tracking of protected marine species via passive acoustic monitoring; improved mapping of essential fish habitat and surveys of marine ecosystem goods and services for impact assessments; cost effective geophysical surveys; advanced sub-meter, sub-bottom sensing methods; and effective atmospheric remote sensing techniques and modeling efforts are but a few of the potential gains to be made for the offshore wind energy industry by accelerating the transition of State of the Art methods into the State of the Practice. Each have the potential to directly lower the risk or uncertainty and cost of offshore wind energy installations. A series of appendices, written by contributing authors, are included to provide additional details about the needs and potential improvements in specific topic areas.

Ocean Test Bed Structure: Using both structural and coordinating facilities in areas representative of existing or potential wind energy areas over the U.S. outer continental shelf, ocean test beds would advance knowledge of the site characteristics and impacts by providing public benchmark datasets for testing innovations in resource characterization. Distinctly different than privately held survey data, these data sets would serve as national standards against which innovations are measured and evaluated for their potential to become regulatable, bankable and insurable. Via direct comparisons of State of the Art methods and techniques for site characterization or Metocean validation and open data repositories for desktop-study analysis of methodological efficacy, OTB activities would contribute to reduced project costs, mitigate perceived risks, and contribute to a streamlined permitting process. Viewed as research and innovation infrastructure, OTBs would be part of a network of large-scale national testing facilities, laboratories, and platforms sponsored by public, private, and research partnerships.

Ocean Test Bed Case Study: As an example of how an OTB would be organized and what it might focus on, a case study for an OTB in the coastal waters south of Massachusetts and Rhode Island is presented. As conceived, the Mass/RI OTB would collect benchmark datasets directly relevant to five existing federal lease areas and include stakeholders from industry, government, and NGOs, along with researchers and ocean users. The Mass/RI OTB would conduct applied research on focus areas including: Marine Mammal mitigation strategies, cost effective high-resolution geophysical surveys, cable burial monitoring, and structure loading during extreme events, as well as advanced research on atmospheric boundary layer sensing and prediction. 


\section{$\underline{\text { Table of Contents }}$}

\section{Introduction}

- The Problem with the 'Proof Factor'

- The Motivation for and Importance of a Fresh Approach

- The Goal of this Document

\section{State of the Industry}

- The Potential Industry

- The Opportunity

- The Grand Challenges

\section{State of Ocean Science Research}

- A Historical Look

- The Next Big Thing

- Applications of Science to Ocean Planning

- Roadblocks

\section{Transitioning Art into Practice}

- Research, Development, and Validation Topic Areas

- Preview of Detailed Appendices

\section{Conceptual Design of an Ocean Test Bed}

- Purpose and Need

- Science Framework and Benchmarking Process

- Organization

- Development Tasks

- Benefits

7 Case study: A New England Shelf Ocean Test Bed

- Background

- Proposed Design

- Technologies Advanced

- Potential Lessons Learned

8 Conclusions and Suggested Course of Action

9 Acknowledgements

10 References

Appendices 


\section{Introduction}

- The Problem with the 'Proof Factor'

- The Motivation for and Importance of a Fresh Approach

- The Goal of this Document

\section{The Problem with the 'Proof Factor':}

Harnessing the energy of the wind blowing over the outer continental shelf (OCS) to produce electricity is a rapidly growing field in the United States. With more than ten separate federally regulated lease areas already under development between Cape Cod and Cape Hatteras alone, it is certain that the first large-scale offshore wind energy infrastructure project will be built within the next five years.

Particularly for these initial offshore wind (OSW) energy systems, detailed knowledge of the physical environment where installations will operate is key to safe and effective design, permitting, construction, and operation. Environmental monitoring is needed not only to characterize the wind resource itself, but also the potential risks present within the construction and operation of a new project in an unfamiliar ocean, in order to determine whether or not projects are both economically viable and environmentally sound.

The cost of developing OSW installations is larger and more complex than onshore wind installations for two key reasons. First, much of the total project costs are physically in the ocean. Turbine foundation systems can comprise up to half the cost of an installation itself, and the structural design characteristics are partially controlled by the particular ocean environment of the installation location. As a result, a large part of the uncertainly or risk for projects is 'in the ocean' as well. Thus, any action that reduces this risk or increases the information available for decision-making will, by extension, reduce the overall project costs and lower the resulting cost of energy to ratepayers. Secondly, wind energy is a new stakeholder and U.S. Federal law (BOEM 2015) obligates OSW regulators to ensure that activities related to offshore renewable energy development in the OCS are conducted in a manner that protects both the environment and the rights of other authorized users of the OCS. This requires a higher level of preliminary data collection activities and stakeholder engagement to both characterize the resource and the design criteria present as well as understand the potential impact of projects on the ocean environment and ocean users as compared to wind-energy development on land.

The current body of resource characterization technologies utilized by both the European offshore (e.g. BSH 2011, 2013; Carbon Trust 2015; 2018) and the U.S. onshore wind (e.g. AWEA standards) energy industries have

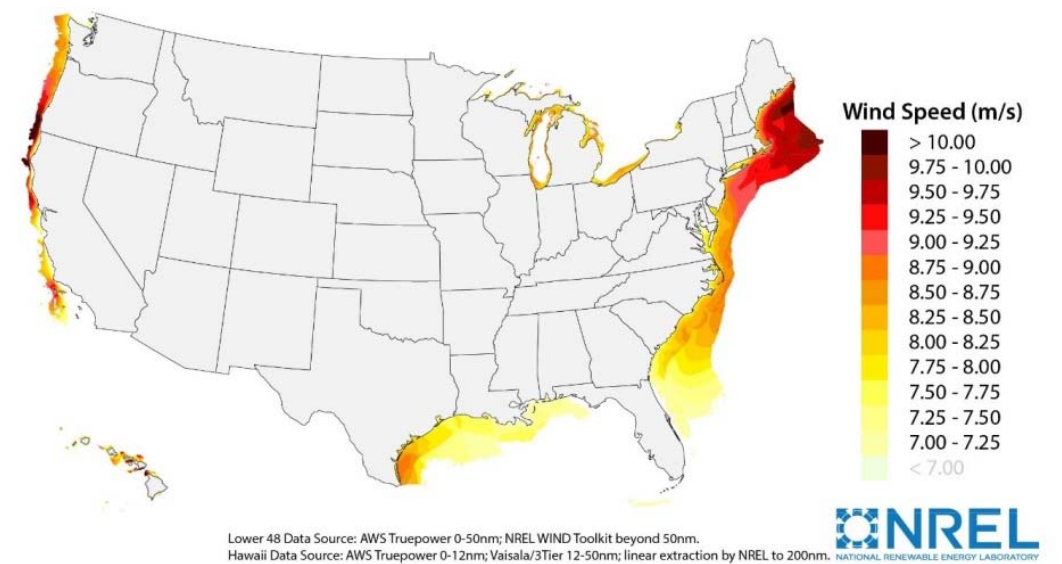

Figure 1: Reanalysis model estimate of average wind speed at hub height for the U.S. outer continental shelf (OCS), made by the National Renewable Energies Laboratory (NREL). Image credit: NREL 
recognized track records that provide a basis for accepted methodologies (i.e. the state of the practice) within the emerging U.S. OSW market. However, this set of approaches is inadequate for the challenging mix of site conditions present in the U.S. (DOE-DOI 2016), particularly along the eastern seaboard where near-term development is focused. Today, with the rapid advancement of micro-computing, autonomous surface and underwater robotics, and physical and biological sensing technologies in the ocean science community, there exists a new and developing body of technologies (i.e. the State of the Art) with the potential to revolutionize our understanding of the ocean characteristics critical to OSW systems, with additional benefits of mitigating risk and reducing costs.

The principal barrier to the widespread development and application of next generation ocean technology is the "proof factor." These technologies, as promising as they are, have yet to develop the body of evidence required to overcome reticence towards their adoption by the regulatory, scientific, engineering, or investment communities needed to support their full application. Open validation of the efficacy of measurement methodologies or regulatory goals would lead to reduced cost of data acquisition and permitting timelines, improved impact mitigation, and, in the end, lower development risk. Thus, what is needed is a pathway, or framework, to rapidly move innovations toward implementation; to advance the permitting process through systematic validation; and to improved modeling, monitoring, and analysis in an open process by neutral parties. With the U.S. sector of this industry in its infancy, and site conditions differing significantly from established projects in Europe (i.e. Musial and Ram 2010; Sirnivas et al. 2014; DOE-DOI 2016; EY Report 2015; Wind Europe 2017), there are multiple potential avenues in which the U.S. research community can advance and streamline observational and modeling components of site characterization efforts.

\section{The Motivation for and Importance of a Modern Approach:}

Since 2016, the Massachusetts Research Partnership for Offshore Wind Energy and other Partnership for Offshore Wind Energy (POWER-US) partner organizations have worked to convene a series workshops and meetings (http//:www.power-us.org) in order to understand the science needs of this growing field in the U.S. Following the strategic goals of the industry and U.S. federal government (e.g. DOI-DOE 2016), the POWER-US effort focused on understanding the challenges to reducing costs and technological risks of site characterization. Current best practices (e.g. BOEM 2015), operation and monitoring efforts of existing installations (e.g. BSH 2013), and State of the Art methods were surveyed by representatives from a broad swath of the academic, agency, and industry groups in order to fully assess the challenges facing the industry.

It is clear that new methods and techniques being used in ocean science research have the potential to yield benefits to the emerging U.S. offshore wind energy industry that could lower costs and better mitigate environmental issues. The recent publication of the National Offshore Wind Strategy Report (DOE-DOI 2016) by the U.S. Department of Energy (DOE) and the U.S. Department of Interior's Bureau of Ocean and Energy Management (BOEM), laid out the need to facilitate technology transfer, and the impetus to develop the required infrastructure and methods testing facilities. The present paper fits in directly with the strategy outlined in the National Strategy report, which contains the specific recommendations that the activities discussed here aim to accomplish, including:

Strategic Theme 1 - Advancing the Industry through Reducing Costs and Technology Risks Action 1.1 - Power Resource and Site Characterization

- Support Site Characterization data collection guidance;

- Gather and Disseminate U.S. Met-ocean and (Ocean) Geologic data; and

- Validate Innovative Site Characterization Methods. 
These activities support an overall societal goal of advancing ocean-related science and engineering while at the same time advancing ocean energy concepts that are at the core of the long-term vision of domestic offshore wind development. Such efforts would also facilitate the validation of technologies that can support, enhance, and generate a positive economic impact on a host of industries and ocean activities, both in the U.S. and globally.

\section{Why now:}

As described in the National Strategy report (DOI-DOE 2016), it is critical to set these ideas and concepts now along with the framework, or pipeline, for developing new ones while the industry in the U.S. is emerging. While the OSW industry in Europe is a number of years ahead of that here in the U.S., it is clear from their lessons learned (e.g. MMO 2014; BSH 2013) that developing this infrastructure for technology transfer early in the development of the industry will pay dividends long in the future.

\section{Goal statement:}

Via this document, POWER-US seeks to develop the concept of Ocean Test Beds (OTBs) as research and development infrastructure capable of driving innovation in the modeling and monitoring of the physical, biological, use characteristics, and impacts of offshore wind energy. Similar to large-scale national testing facilities (e.g. EERI 1995) created to advance American knowledge and innovation, OTBs would advance knowledge of the continental shelf geologic, oceanic, biologic, and atmospheric conditions in areas of active development for U.S. OSW industry as well as provide public benchmark datasets for testing American innovations in resource characterization.

This document motivates the need for OTBs both from an industry and science perspective before presenting details on known concept areas that would clearly benefit from OTBs. A framework for how OTBs could be organized as partnerships between ocean stakeholders such as industry; federal, state, and local government agencies; commercial and recreational fisheries; NGOs; and researchers is then described and a case study motivating the development of an OTB near the Massachusetts and Rhode Island Wind Energy Areas (WEAs) is presented. The Mass/RI OTB would establish the proof of concept testing needed to move the State of the Art into the State of the Practice and potentially extend an

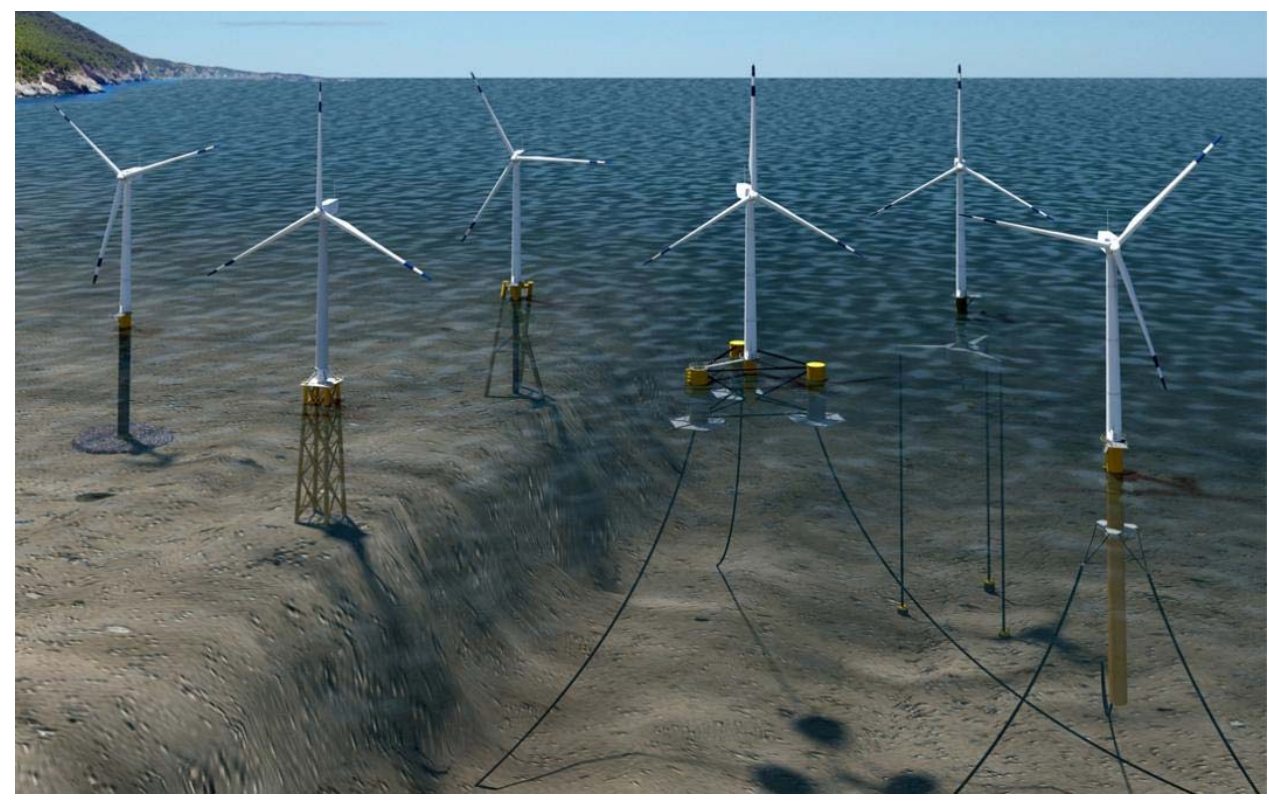

Figure 2: Cartoon of the various types of potential foundations available for offshore wind energy installations. Image credit: NREL. 
existing observatory offshore to create a long-term reference station.

\section{State of the Industry}

- The Potential Industry

- The Opportunity

- The Grand Challenges

\section{The Potential Industry:}

The U.S. has extensive wind resources off of its coasts capable of generating a significant amount of the energy needed to replace retiring power generation facilities in a clean and renewable manner (Musial and Ram, 2010). The advantages of obtaining power from offshore wind are clear and have the potential to alleviate much of the U.S. coastal area's concerns about future power generation. Putting numbers behind this concept, the National Strategy report (DOI-DOE 2016) estimates of the potential benefit of OSW to the economy and provides a strategy to build the capability to allow for the development of that power source. In the report, the potential benefits of OSW are described in terms of Market Opportunity within the U.S. coastal areas, which could reach an installed capacity of $3 \mathrm{GW}$ of power by 2020 , an installed capacity of $22 \mathrm{GW}$ of power by 2030 , and an installed capacity of $86 \mathrm{GW}$ of power by 2050. In terms of amount of energy delivered in Terrawatts (TW) per year, the report suggests that as much as 12 TW could be delivered by OSW by 2020,87 TW by 2030 , and 339 TW by 2050 . The report points out that the Opportunity Space Utilization that could be filled by offshore wind energy in the U.S. by 2050 could represent $14 \%$ of the total electric value of the Opportunity Space (i.e., $14 \%$ of the total electric generation power expected to be needed by 2050 - or $14 \%$ of 2,380 TW per year).

One of the principal challenges to the adaptation of OSW as a power generation source in the U.S. is the comparative cost of OSW energy installation, and therefore, generation when compared to the current

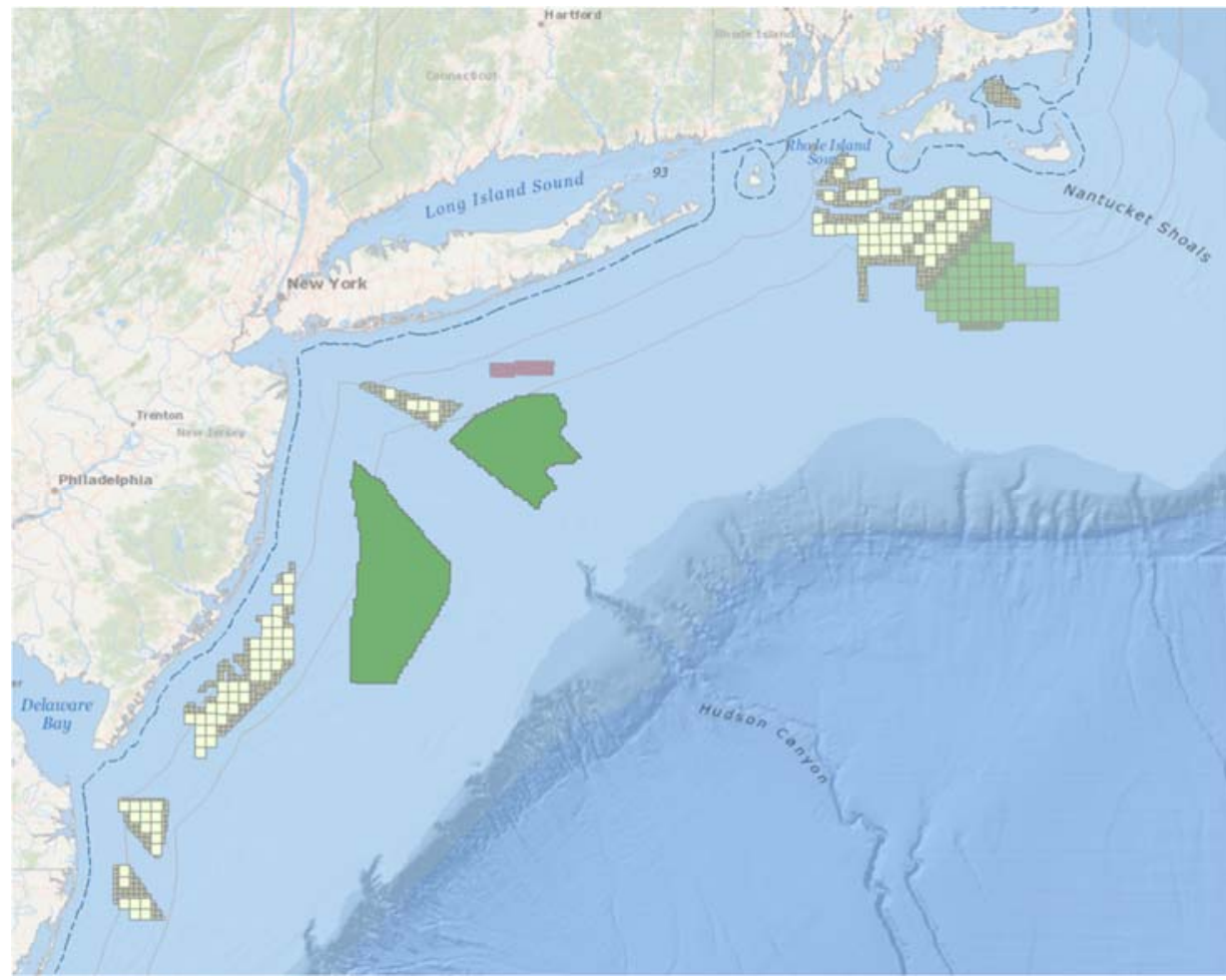

Figure 3: Existing (yellow, grey) and proposed (green) Offshore Wind Energy lease areas along the MidAtlantic Bight of the Atlantic Outer Continental Shelf. Image generated using BOEM and NOAA's Marine Cadastre National Data Viewer. (https://marinecada stre.gov/nationalvie wer) 
and projected cost of other power generated with more traditional fuels such as natural gas. One of the key strategies outlined in the National Strategy report (DOI-DOE 2016) is the development of a pathway to achieve competitive costs. A large component of the cost factor in OSW is the capital cost of developing wind farms and the operation and maintenance costs. Uncertainties in the estimates of power production and design characteristic of particular sites amplify project risks and, by direct extension, project costs.

\section{The Opportunity:}

Both of these factors can be significantly reduced through the development of more efficient and effective ocean characterization methods. In decades past, U.S. technologies such as ship-based geophysical exploration of the sea bed beneath the ocean floor provided new ways to understand the complex layering of the ocean geology, and eventually became the standards by which information gathering and decisions concerning ocean development were made for the U.S. oil and gas industry. The current State of the Practice in ocean characterization that developed over this timeframe has provided information upon which regulatory, engineering, design, and financial decisions are made for all ocean projects, including OSW (BOEM 2015). However, the site characterization needs of OSW are distinctly different from what oil and gas-centric technology is able to provide. For example, OSW characterization requires high-resolution characterization of the first $50 \mathrm{~m}$ of the sub-bottom over small horizontal areas as opposed to kilometers below the sea bed over wide areas. With these sampling needs in mind, autonomous underwater vehicle (AUV) based geophysical sampling represents a potentially ground-breaking innovation in OSW site characterization, particularly in areas of highly heterogeneous sediment types.

\section{The Grand Challenges:}

In addition to the potential role of AUVs in carrying out site characterization activities, a survey of industry groups including manufacturers and developers but also financers, fabricators, designers, and consultants have identified a number of key Grand Challenges in Site Characterization, including:

Maximizing domain awareness to minimizing impacts on critical marine mammal species: Existing regulations meant to protect critical marine mammals have high levels of uncertainty in their efficacy and are cumbersome to implement. This is particularly true in the Mid-Atlantic Bight due to the presence of the highly endangered North Atlantic Right Whale. The current state of practice, as set by BOEM regulations entails multiple ship-based observers during intense site activities, multiple aircraft overflights, as well as significant uncertainty. In recent U.S. installations, construction windows were also narrowly set to avoid perceived high impact time periods. Alternative methods that utilize advanced sensing of protected marine species have the potential to offer a higher degree of risk mitigation while also reducing regulatory overhead and streamlining site-related construction activities.

Advancing infrastructure development while preserving the marine ecosystem's goods and services: Offshore Wind Energy has a permitted requirement to avoid additional disturbances of existing oceanbased uses or stakeholders. As a result, the commercial and recreational fisheries are an important stakeholder to address within a development plan. However, a broader understanding of the effects of the installation on the greater ecosystem could provide a more nuanced understanding of the potential interactions. To better facilitate this holistic approach, advanced mapping of essential fish habitat (e.g. Gallager et al. 2005), quality baseline surveys, and ecosystem monitoring are required within an open framework with regulatory feedback to best minimize potential impacts. 
Novel, high-resolution geophysical techniques: Complementing cost-effective geophysical surveys using AUV technologies, advanced sub-meter, sub-bottom sensing methods are required to improve foundation design and reduce construction risk within the unique U.S. shelf conditions. Numerous areas of the U.S. coast have heterogeneous sub-bottom sediment types, making the need for efficient high spatial resolution measurements of the sub-bottom a key component of lowering overall project costs.

Building an accurate hindcast/forecast of the atmospheric boundary layer: As site characterization is a significant cost to developers early in the project process, more cost-effective ways to measure and predict both the wind present over the OCS as a resource (i.e. the fuel for OSW energy) as well as a design criteria for engineering structures and installations are needed to lower the pre-financing cost of an installation and increase the certainty of potential power estimates used to achieve project financing. Testing/evaluation of new Metocean sensors and remote sensing techniques for cost-effective data sources to assimilative forecast models of the time varying resource will be necessary to aid grid integration of OSW as a power source (e.g. DFFV 2015).

The continued development of ocean technology and innovation will play a key role in driving the OSW industry forward, in much the same way as the development of a domestic supply chain allows markets to increase scale and lower costs. The ocean environment has to date yielded an enormous benefit to the economies of the world, and knowledge of the ocean characteristics is a commodity that has extreme value. In the areas of minerals and fossil fuel exploration, shipping, fishing, transportation, defense, ocean energy, subsea pipeline and electrical cable infrastructure, and telecommunications, the composite value of ocean activity is measured in the trillions of dollars per year. Even a small increase of $1 / 2$ or 1 percent in efficiency within these industries through better ocean characterization due to innovation and new technology adaptation will have a profoundly positive impact on the economic calculus of ocean-related activities. The potential benefits are significantly more substantial for OSW.

\section{State of Ocean Science Research}

- A Historical Look

- The Next Big Thing

- Applications of Science to Ocean Planning

- Roadblocks

\section{A Historical look:}

Advancement in ocean science and technology over the past 50 years has dramatically increased our understanding of the ocean realm. A portion of the development of ocean characterization innovation over that time was driven directly by the need for data to support either commercial or military information needs. However, a second, critical force driving innovation in sensor technologies and analytical methodologies has been the need to resolve basic questions about the nature of the ocean and its role in our climate system, biological productivity, and ocean exploration (NAS 1951; NAS 2000). Technologies such as ship-based marine geophysical exploration of seabed characteristics, mooring technologies for station monitoring of meteorological and sub-surface conditions, satellite and airborne sensor observations, data assimilative modeling, and optical imaging of marine organisms for biological diversity mapping and ecological monitoring, and assays for identifying specific species or toxins (e.g. Anderson et al. 2012) are examples of the State-of-the-Practice in ocean characterization that have come directly from the development of technologies purpose-built for basic ocean science research. 
Figure 4: Real Time whale sensing technology via passive acoustic sensing depends on acoustically quiet buoy systems and direct knowledge of the time and space depend detection range thresholds. Efforts to understand variability in ranges and mammal behavior are ongoing. Image credits: M. Baumgartner and WHOI.
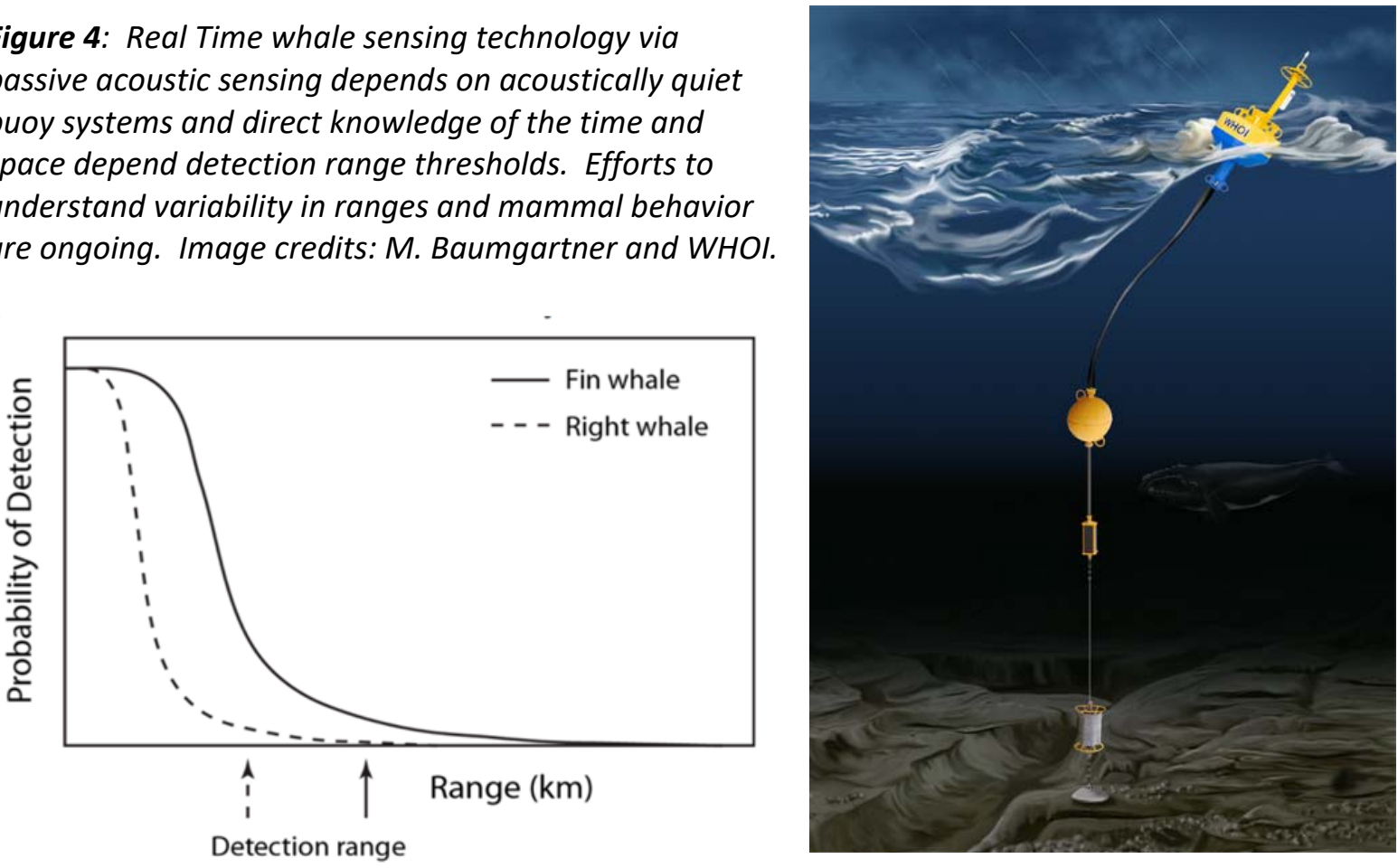

From these efforts, a robust understanding of the general atmospheric, physical oceanographic, and geologic character of the ocean emerged that has allowed the development of an advanced ocean economy as well as aspects of the emerging OSW industry itself. Many of these developments also represent the current set of tools that regulators, developers, commercial interests, and the military rely on to make decisions concerning ocean activities.

\section{The Next Big Thing:}

Thus, the path toward continued innovation in ocean characterization should look toward the state of the art technologies being used now for basic science research for potential transformative methodologies that will push the next phase of industry forward. For example, ecologist have recently developed advanced acoustic sensing methods, autonomous, acoustically quiet platforms, and algorithms for automated detection and real-time reporting of marine mammals in order to understand whale foraging ecology (Baumgartner and Mussoline 2011).

Advanced research on the dynamics of the solid earth on the tectonic scale have developed pioneering new methods for 'high' resolution geophysical remote sensing (e.g. Lin et al. 2013; Siegel et al. 2014). Regional climate experts have successfully built coupled oceanic and atmospheric modeling systems that incorporate new sensing tools into the data assimilation process resulting in higher fidelity estimates of the past atmospheric or oceanic states (e.g. James et al. 2018; Yu et al. 2012). Collaborations between researchers and fisheries operators have placed new sensors on traps and nets to build integrated databases of the physical and biological conditions of the continental shelf (e.g. Goulette et al. 2014). Experiments of the structure of biological communities in unbounded systems (i.e. the open ocean) and the flow of biologically available energy and energy efficiency are paving new ground in the important role of food web analysis in ecological assessment activities. 


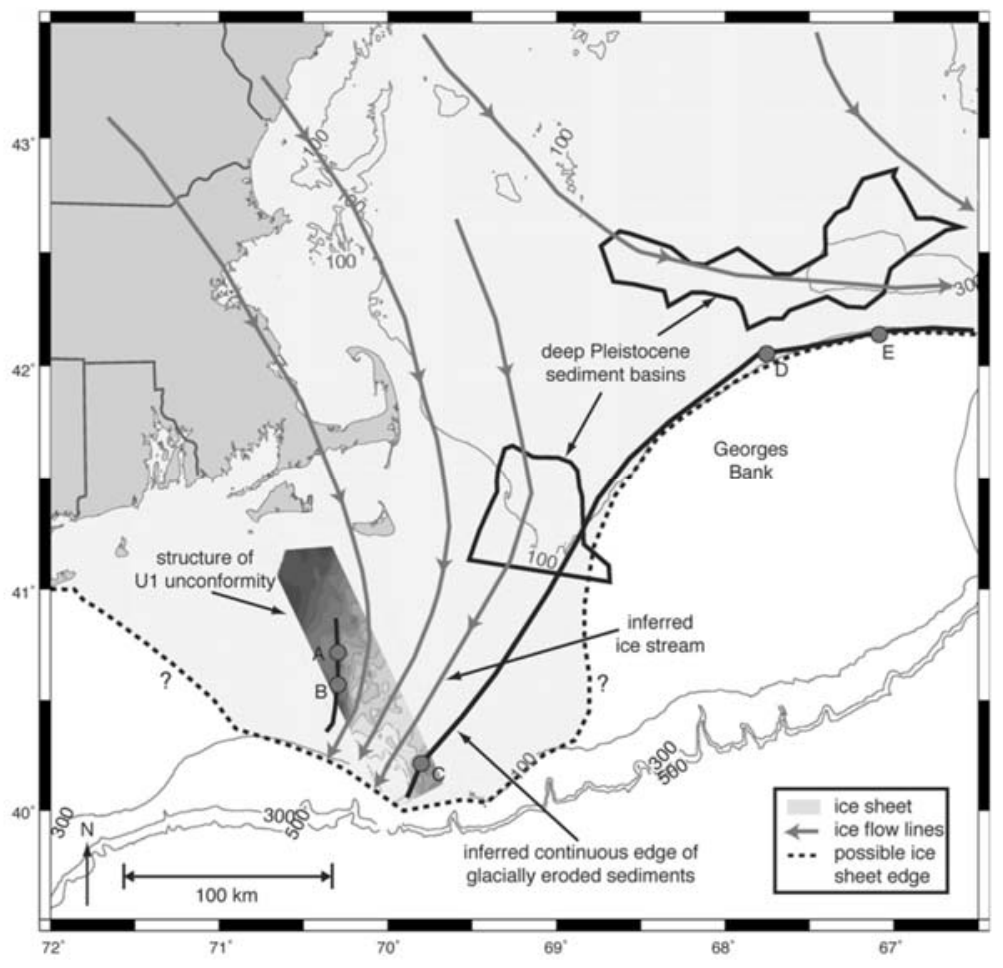

Figure 5: Source of the 'boulder problem' of the U.S. East Coast Continental Shelf. The path of late Pleistocene ice streams inferred from dramatic erosional features observed in high resolution seismic data suggests that much of the wind energy areas of the New England Shelf contain large fractions of 'glacial erratics,' i.e. large boulders, that complicate construction efforts. Reprinted from Siegel et al. 2014

\section{Applications of Science to Ocean Planning:}

The recent Rhode Island Ocean Special Area Management Plan (RI OceanSAMP:

http://seagrant.gso.uri.edu/oceansamp/ ) process is a prime example of the successful inclusion of basic science research and methodologies directly into the planning process. Studies of all aspects of the Rhode Island shelf (i.e. Grilli et al. 2012; Grilli and Shumchenia 2015), including social science components and use scenarios (i.e. Figure 6), were conducted by researchers in direct interaction with ocean users. This effort resulted in an integrated, informed approach to pre-determining optimal areas for OSW development (McCann et al. 2011), how existing users and ecosystems would be impacted, and what potential problem areas may need to be managed during the development process. Unrelated to OSW, the California-led task force on Marine Protected Areas in state and federal waters (Gleason et al. 2010) serves as a model both testing and verifying new methods for sampling the marine environment as well as for building the organizational framework necessary to apply the results of those studies within a community accepted process. This process invoked new methods for ecological assessment, baseline surveys, and ecosystem-based management to determine the layout of marine protected areas that was most likely to meet all user needs. The common thread in both examples was the integration and verification of cutting-edge observation, methodological, and analysis methods pulled directly from basic science research into new applications that served the stakeholder led and developed process.

In contrast to these successful planning efforts, the regulatory decision-making process for U.S. OSW is motivated by risk-related considerations based in part on oil and gas regulatory frameworks, and limited adaptation of variations to the current regime have been made. Stated differently, regulations and regulatory decisions currently being made are based on conventional methods and there is little ability in the system to adopt new processes or technologies in a timeframe that will allow new techniques and methodologies to significantly affect the initial development and growth of the industry. It should be noted that both BOEM and individual developers do test novel approaches on a project by project basis, but there is no systemic way to validate new methods to efficiently achieve industry-wide advancement. 


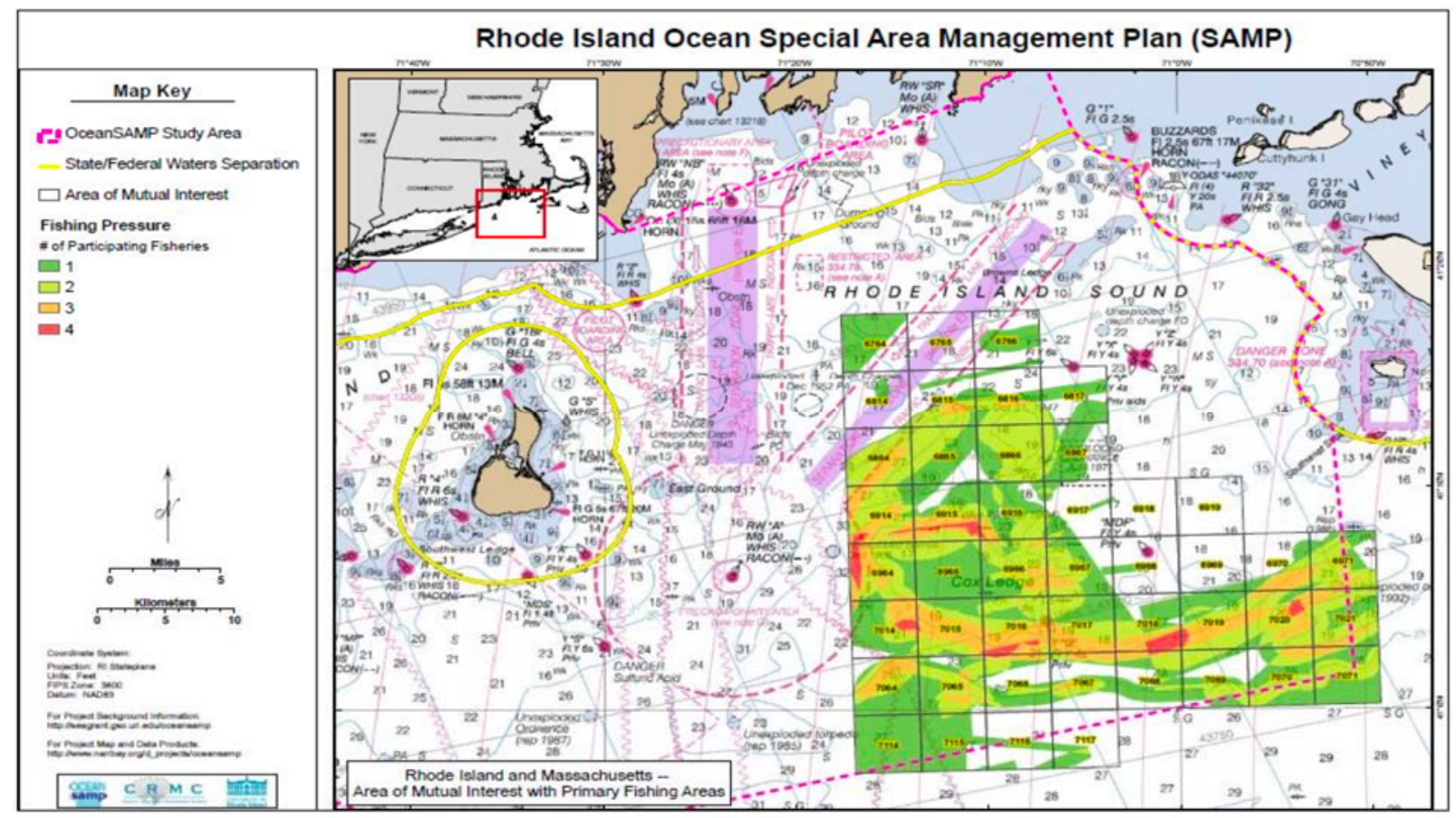

Figure 6: The RI Ocean SAMP planning process led to the delineation of the available lease blocks with the fewest potential impacts and the technical readiness. Fishing pressure within the viable lease areas is shown here, which was used to further limit available areas. Image credit: RI Ocean SAMP.

\section{The Roadblock:}

Improved understanding of the physical environment where OSW energy systems will be operating can streamline development, maximize energy production, and minimize impacts. With site conditions in the U.S. differing significantly from established projects in Europe, it is clear that advances in estimating the atmospheric boundary layer, remote sensing of critical marine species, monitoring and protecting fisheries resources, and geophysical remote sensing by the U.S. research community will yield dividends to industry. The two years of efforts by the Massachusetts Research Partnership on Offshore Wind Energy have consistently found that industry groups are ripe for the inclusion of new methods and techniques. However, advances in resource characterization need to be validated in an open and standardized way, suggesting that a benchmarking process is needed here as well to move existing or future state of the art methods in site characterization into the state of practice for the industry.

Efforts to better understand, map, and characterize ocean conditions contribute directly to the economic calculus of activities that occur offshore. In many ways, the development of ocean research and technology are a direct driver of the development of the ocean economy (i.e. the blue economy). These activities can provide: a regulatory basis upon which development in the oceans can occur, the scientific and engineering basis through which the design of ocean projects are undertaken, and the reduced risk factors that allow financiers and insurance interests to develop projects that are more advantageous to the local communities as well as ratepayers. 


\section{Transitioning Art into Practice}

- Research, Development, and Validation Topic Areas

- Preview of Detailed Appendices

Following the strategic goals of the National Strategy Report (DOE 2015); current best practices (BOEM 2015), operation and monitoring efforts of European wind farm areas (BSH 2003, 2008, 2011, 2013), initial monitoring efforts at existing OSW turbine sites (AWS-Truepower 2015), and State of the Art methods were surveyed (MRP 2017) to understand the potential for new innovations to assist industry in reducing the costs and technological risks of site characterization. Six (6) topic areas in which nearterm efforts to transition existing state of the art methods into the state of the practice are introduced below. Each are described in general terms that reflect the scope of the problem, the stakeholders involved, and potential paths toward meeting the research goals. Additional details on the pathways by which such methodologies could be developed, validated, and adopted are discussed in the appendices to this document. It is important to note that these represent a subset of the potential state of the art methods of critical aspects of site characterization that have the potential to pay dividends toward improving the development of the U.S. OSW industry. Other areas exist that were not included, and the OTB framework discussed below would be able to identify and develop similar state of the art to state of the practice translations for more areas of concern than those described here.

\section{Marine Mammal Tracking and Prediction:}

Existing marine mammal exclusion distances for construction/O\&M activities are relatively untested for their efficacy and expensive to undertake. At its core, the objective of marine mammal monitoring is to find all the individuals of a protected or important species and guide OSW operations around them so as to minimize interactions as well as potential harmful effects. Thus, advanced sensing of protected marine species has the potential to reduce regulatory overhead and streamline site-related activities. The potential stakeholders with interest in this challenge include regulators focused on marine mammals, environmental NGOs focused on endangered species, developers planning and completing construction activities, and operators completing O\&M activities.

Networks of passive acoustic monitoring stations or mobile assets represent an attractive way, in parallel with aerial surveys, to ensure better data collection and responsive site actions. However, this type of technological advancement (Figure 4), which is readily available to researchers, is untested as a regulatory framework. Advance work on localization and ranging is required to bring this promising advancement to fruition in a framework that provides benchmarked testing of new methods for sensing during activities. Following the National Academies National Research Council (NRC) efforts on species specific effects, building models to test species-specific notifications should also be done. While the continued acoustic sensing of near-term projects (e.g. BOEM RODEO) are contributing toward advancing the modeling of the acoustic environment and potential mitigation methods, a more holistic, validated, approach is necessary. See Appendix A for more information.

\section{Ecosystem monitoring to understand the effects of OSW installations:}

At the scale envisioned, wind farms will have significant interactions with the marine environment, and marine ecosystems. How might these interactions be managed most effectively such that the goods and services produced by the continental shelf and its plants and animals are able to exist synergistically with planned activities is an important and unanswered question. Potential stakeholders include all users of marine ecosystem services, from marine shipping and commerce, energy extraction itself, to commercial and recreational fisheries (discussed in more detail next). 
Near-term objectives include the need to identify existing datasets and data needs in order to produce quality baseline surveys of the pelagic and benthic habitat, stock assessment, and economic priorities. Rapid, no-take survey technology is progressing rapidly, with commercial systems available to carry out sampling for pre- and post-construction surveys well as O\&M surveys to assess ecosystem state. Advanced mapping of essential fish habit, high-resolution baseline surveys including both ship-based and satellite-derived observations, and sustained ecosystem monitoring are required within an open framework with regulatory feedbacks to minimize potential impacts. While some aspects of this topic area are being actively pursued (i.e. BOEM's current RODEO project to monitor construction activities for biological impacts), more is needed. See Appendix B for more information.

\section{Fisheries mitigation research efforts:}

The Bureau of Ocean Energy Management (BOEM) is obligated by federal law to consult with the NOAA National Marine Fisheries Service and respond to findings related to the requirements of the MagnusonStevens Fishery Conservation and Management Act (MSA) as well as other federal statutes related to fisheries and fisheries management. A series of workshops and reports have gathered input from state and federal agency representatives, fishing industry representatives, offshore wind developers, and

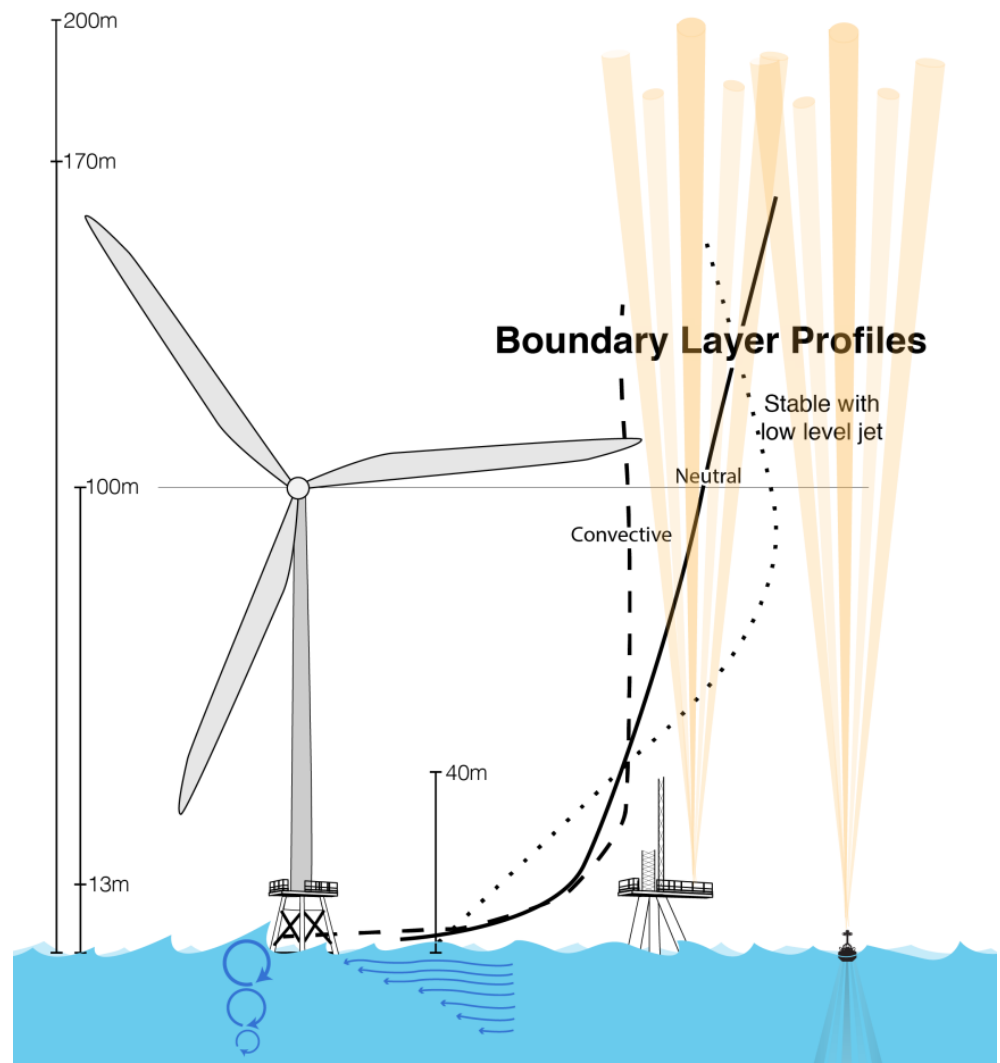

Figure 7: Schematic of the various marine atmospheric boundary layer wind speed profiles over the coastal ocean relative to a potential wind turbine, the potential oceanic forces important to turbine construction and operation, and our present-day abilities to sense them both via fixed sensors and remote sensing. Image credit: WHOI. fisheries research scientists from public, private, and non-governmental research organizations (e.g. PetrunyParker et al. 2015; Stephenson et al. 2017). A present goal of a National Academies of Sciences committee (NAS 2018) is to gather stakeholders and identify issues of concern and develop an operational framework for how to understand/assess: (1) the impact of individual projects on key species groups and (2) the cumulative impact of multiple projects. A variety of efforts have been conducted or are underway to begin to identify potential impacts of offshore wind activities and infrastructure on fishing and fish populations and to develop plans and approaches to avoid or minimize negative impacts (e.g. Ecology and Environment 2014; Kirkpatrick et al. 2017). These include effects of increased vessel traffic on fisheries activities, cable electrical field effects, and impacts on potential exclusion zones on the industry. However, these topics require additional science- and stakeholder-driven efforts. See Appendix $\mathrm{C}$ for more information. 


\section{Atmospheric boundary layer research to improve hindcast and forecast models:}

LIDAR-based sampling of the atmospheric boundary layer and the potential wind energy resource available at the level of the turbines themselves is rapidly becoming the standard for static or historical site assessment (Figure 7). While this represents a sizable cost savings and risk reduction over previous methods toward understanding the historical potential for wind as the fuel for driving the energy production, deficiencies exist in our ability to: (1) use the same methodologies to observe the windbased design conditions (i.e. the turbulent loading of the turbine, shear characteristics, etc.), and (2) accurately predict the future and most importantly the near-future (10-60 minutes) winds present over an installed system. Knowledge of the wind resource and turbulent characteristics is needed at time and space scales shorter than what is presently available to best inform all aspects of offshore wind energy extraction, from improved estimate of bulk resource to short term forecasts of wind/wave conditions for constructors, grid operators, and suppliers (ESRL 2013; Freedman et al. 2010).

Potential stakeholders with interest in this challenge include: regulators for power assessment, developers for reduced risk/cost in resource characterization, grid operators for short term power output, and insurance and finance groups for risk assessment and operations assessment. Efforts toward this challenge area would focus on evaluating new Metocean sensors and remote sensing techniques to be effective data sources of the necessary wind parameters in open ocean, or marine, environments. Advancements in our understanding of turbulent mixing near the ocean surface and the flux of momentum, heat, and water vapor between the ocean and the atmosphere are required to increase model fidelity.

Short -term forecasts represent an especially important product for future grid operators, and are a critical component of efficient and effective OSW operations. High fidelity predictions require intensive efforts to couple massive amounts of in situ observations with high resolution data assimilating numerical models of the time varying wind energy resource. Thus, both the development of costeffective, spatially dense observations with a robust, standardized numerical modeling system is required to produce regional atmospheric state estimates at appropriate time and space scales. See Appendix $\mathrm{D}$ for additional details.

Advancing geophysical and geotechnical knowledge and sampling of the sub-bottom environment: Geophysical and geotechnical surveys are costly, time consuming, and represent a high-risk part of the development process. In the end, consumers foot the bill for this uncertainty in terms of higher project costs and utility rates. New research on, and uses of, remote sensing methods have the ability to provide cost-effective geophysical surveys and advanced high-spatial resolution (i.e. sub-meter) sensing of the sub-bottom environment. These methods are required to improve foundation design and reduce construction risk within the unique U.S. outer continental shelf conditions (Figure 5). Stakeholders include government, industry, and other recreational and commercial ocean users. See Appendix E for additional details.

However, in a very real sense, data sharing by all parties to consolidate and advance initial understanding of site properties is the first objective that can occur in order to lower the overall public investment. To accomplish this, the assembly of a centralized, standardized repository for all raw geophysical datasets, in which public access is allowed, will aid discovery and testing (at the desktop study scale) of new methods to image the sub-bottom at meter scales and S-wave versus P-wave observational and sensing methods that might decrease the overall cost and time of surveys. This is a 
non-trivial, but critical task as data sharing agreements that allow access to public data and require developers/industry to submit raw data to repositories must be designed carefully.

Autonomous platforms for ocean sampling, platform/structure monitoring, and mitigation efforts: As the example in Section 4 illustrates, AUV-based geophysical sampling, structure health monitoring, and ocean parameter estimate surveys represent a potential paradigm shift in how industry conducts business over the outer continental shelf. Just as aerial drones have revolutionized how aerial survey tasks are carried out in the past few years, the use of, and advancement of, automation in the ocean could revolutionize the survey and monitoring tasks associated with offshore wind construction, operations and maintenance activities.

Social sciences and ocean use planning:

Marine spatial planning efforts, such as the Northeast Ocean Plan (http://neoceanplanning.org/plan/), have been effective in gathering input from a variety of stakeholders and users of OCS resources and in providing access to data and information for decision support through the Northeast Ocean Data Portal (http://neoceanplanning.org/easy-access-to-ocean-data/). However, more work is needed to establish an organizing framework for prioritization of physical and social science research and monitoring efforts.

\section{Conceptual Design of an Ocean Test Bed}

- Purpose and Need

- Science Framework and Benchmarking Process

- Organization

- OTB Development Tasks

- Benefits

\section{Purpose and need:}

Similar to large-scale national testing facilities created to advance knowledge and innovation in a sector of the economy, a system of Ocean Test Beds would advance knowledge of the continental shelf geologic, oceanic, biologic and atmospheric conditions in areas of active OSW development. Solid scientific data on the design characteristics as well as consensus on the impacts of a wind farm on the marine environment are critical to reduce risk, advance public acceptance, and evolve the regulatory process. Coupling the unique conditions present over the U.S. OCS in areas slated for OSW development with the state of the art methods being used by the U.S. ocean research community, the sole remaining barrier to overcome is the 'proof factor.' Thus, an acute need exists for developing the physical and organizational infrastructure to rapidly move innovations in site characterization through systematic validation and into industry best practices and/or regulatory requirements. This process of transitioning the state of the art into the state of the practice requires an open and evolving infrastructure that produces benchmarked data sets to test and evaluate sensors, improves systems modeling, and allows analysis by neutral, disinterested parties.

An individual Ocean Test Bed itself represents a physical section of the ocean whereby a detailed picture of the atmospheric, oceanographic, and/or seabed conditions are developed using currently accepted state of the practice technologies. This robustly understood ocean segment can then be used to benchmark new technologies, giving the technology developer the ability to prove the efficacy of a given technology against known conditions, encouraging a more rapid regulatory and industry acceptance. Thus, the key components of an ocean test bed for site characterization are: identification of an ocean 
space of interest, the collection of the benchmarking data sets, and the creation of mechanisms to test and evaluate sensors and/or new data collection efforts in an open and established framework (Figure 8). Such a system could have a regional focus but would need to be developed and instituted at the national level.

\section{Science framework and benchmarking process:}

The central goal of OTBs as a whole would be to shepherd the transfer of existing research-grade techniques and methods into the best practices of the U.S. offshore wind energy industry. Following a strategy that is directly in line with the Wind Vision Strategic Plan (DOE 2015) and the National Strategy report (DOE-DOI 2016), OTBs would explore the gains between 'practice' and 'art' to transfer technology

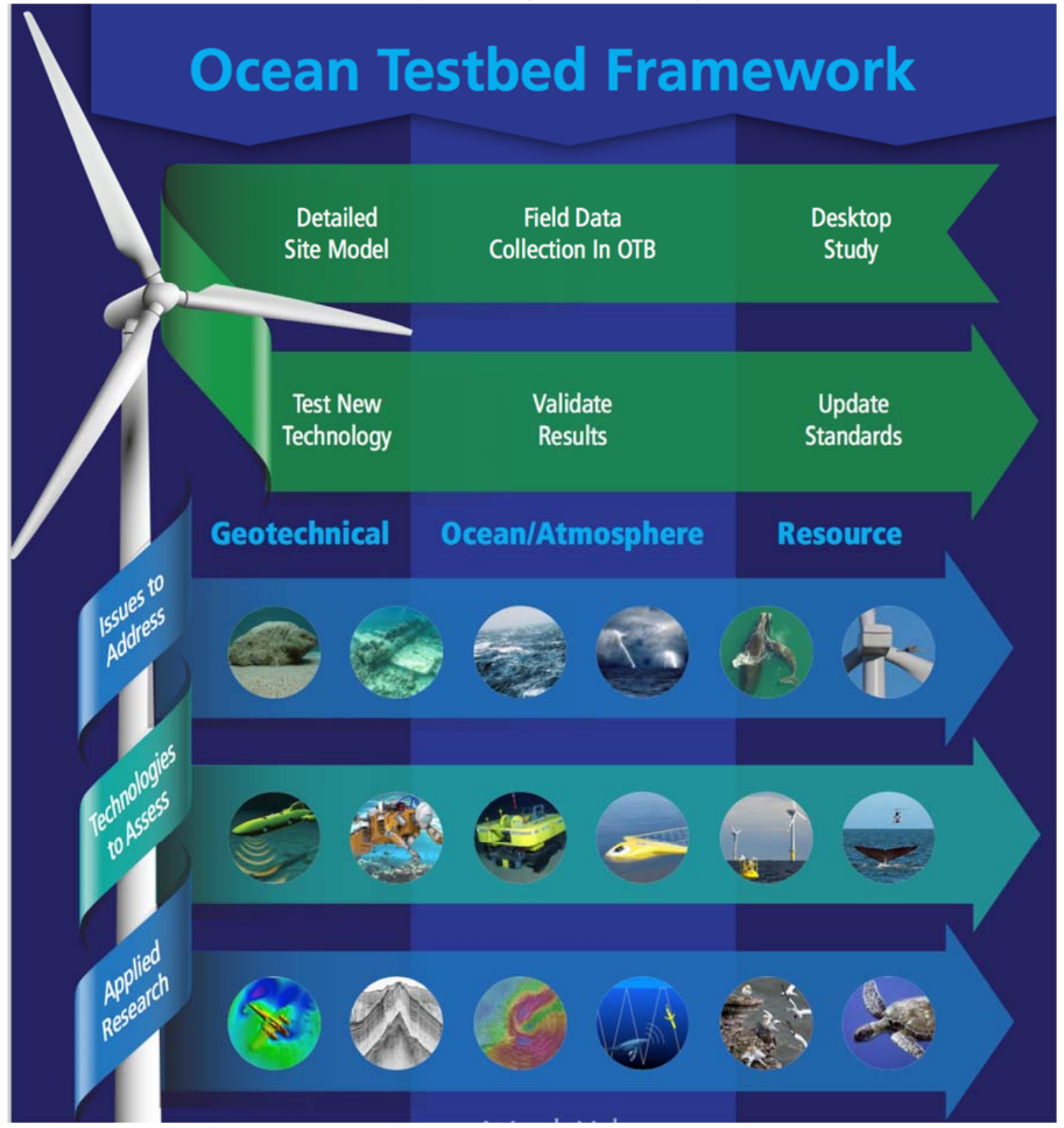

Figure 8: Conceptual Framework for Ocean Test Beds as tools to advance industry and lower the costs and risks associated with Offshore Wind Energy Projects. 
using open-access data sets to provide benchmark comparisons to existing standards (e.g. MMI Engineering 2009; Musial et al. 2010; Offshore Wind Hub 2011; IEC 2011; IEA 2013).

As a second example, the scales of OSW infrastructure projects offer platforms of opportunity for ocean sensors both directly and indirectly related to the turbine's presence. Thus, a viable data collection effort from these platforms that feeds data into the public space has the potential to benefit all stakeholder groups, both for benchmarking new technologies and for long-term monitoring of the impacts of OSW installations on critical habitats and other ocean users that share the continental shelf. In this context, the structure of the data collection effort is distributed, but the repository, sharing agreements, and identification of standards could be instituted at the national level. Such a structure would likely have to be set via the regulatory process, and a central repository maintained to ensure both proper data sharing and availability as well as conformity to potential intellectual property restrictions that may be necessary for some data types. Such a process mirrors the data aggregation agreements that the U.K.'s Crown Estate maintains with industry (i.e. MMO 2014).

\section{Organization:}

OTBs are explicitly meant to be collaborative organizations; composed of partnerships that include industry, government, researchers, and stakeholders. However at least one organization would need to serve as the convening entity, taking the organizational, scientific, and fiduciary responsibility for the OTB. Funding for OTB activities might come from a variety of sources including joint partnerships, grants, and research and development contracts. There are a number of models for how this might be done for OSW, based on existing US industry R\&D centers or as can been seen in how individual European countries have setup OSW R\&D centers. Regardless, the goals and charge of the OTB should be well formed toward the topic area or region in question, focusing the limited resources and timeline of the test bed on specific, tractable research priorities with defined evaluation periods.

\section{OTB Development tasks:}

The size, shape, and organization of an OTB should depend on its focus topics or areas. However, OTBs all would have a series of common development tasks defined here and described in detail below:

1. Desktop Study and Site Identification for the OTB location and structure

2. Design and carry out benchmark surveys of site characteristics of interest via in situ data collection with traditional methods and technologies

3. Curating and public sharing of OTB data sets

4. Testing state of the art technologies against Ocean Test Bed Data sets or and/or competitive technique validation

5. Integration of Ocean Test Bed data into broader scientific and regulatory ocean interests.

(1) Desktop studies: The location and design of an OTB should start with a desktop study in line with the best practices advocated by BOEM in 30 CFR Section 585, as well as the first order technology transfer objectives. Existing public data available through state and federal partners as well as non-profit organizations can help identify potential sites, designs, methods and research questions. Evaluations of these U.S. data sets can be considered in light of the European perspective via collaborations with organizations such as The Crowne Estate, Catapult-ORE, BSH and Fraunhofer-IWES, for example.

(2) Benchmark data collection: Collecting new observations of the area of interest for benchmark testing has three goals: As they should be representative of potential WEAs, they should increase the knowledge base on site-specific characterizations and therefore the pre-project knowledge available to interested parties. They should provide data for direct comparisons of state of the practice and state of 
the art methods or techniques (i.e. benchmarking of innovations). They should also provide for data sets for post-study analysis of methodological efficacy (i.e. input for simulations, development desktop study basis for future innovations).

Benchmark data collection could include the coordinated ocean data collection and synthesis efforts on the continental shelf geologic, oceanic, biologic and atmospheric environments in areas of offshore wind energy development. However, this might also include the construction of research infrastructure (i.e reference stations for OSW research and monitoring) needed to support long-term monitoring and research relevant to the offshore wind industry. As an example, the FINO towers in the German Bight have enabled significant contributions toward understanding power availability and atmospheric properties over the German Bight (BSH 2013). Finally, the development of numerical models that provide specific state estimates of the available resource, or forecasts of ocean or atmospheric variability, including ecosystem models, might be an important component of the OTB data collection phase.

(3) Public data sharing: While publicly funded data collection is routinely available and shared with broad distributions (i.e. A2E repository for DOE-funded efforts), privately collected data on projects within public lands or resources are more routinely closely held and only that information sufficient for the permit or financing is shared beyond the collecting entity. This represents a barrier to successful technology transfer. As described above, many of the challenges in site characterization and other sectors of the offshore wind energy field would benefit greatly from open sharing and access to environmental, resource, structural, and performance data in order to build better statistics or gather a more complete assessment of the problem at hand.

Systematic sharing would allow new methods to be carefully evaluated. Recognizing that the data needs and proprietary bounds are different for offshore wind in comparison to oil and gas is critical. Sensible sharing policies, easy to access repositories, and benchmark comparisons must be implemented at the national level. Data sharing and access agreements must be designed in such a way that protects the proprietary knowledge or methods of the collector but allows public-private partnerships to thrive and work to solve issues of concern for industry as a whole.

In addition, many of the observing systems that can contribute to research on new sensing methods, ocean changes, biological responses, and structural health and design of offshore wind energy infrastructure would benefit from access to structures as measurement platforms. In some cases, access for sensors is required (i.e. fatigue studies). Yet, for a number of reasons, developers are generally not able or willing to host sensors or collaborate on data collection unless it is a requirement of the operational permit.

(4) Art to Practice transitions: Advances in resource characterization need to be validated in order to gain acceptance as an acceptable standard in industry or alter the regulations that govern the OSW's use of public spaces. This is critically important now within the emerging U.S. industry both for public acceptance and environmental protection of the early projects as well as to achieve the cost reductions that will propel the industry forward. The OTB data collection efforts described above could be coupled with defined criteria for advancement that would allow a technique proposer to definitively show, via comparisons to the benchmark data, methodological efficiency or effectiveness. How these transitions would be validated is dependent on the data/research need in question. The UK's Carbon Trust's efforts to systematically validate floating LIDAR as a resource characterization strategy provides a sample pathway to how validation could occur. However, a second example is the ongoing U.S. Bureau of 
Reclamation's Sub-Seasonal Climate Forecast Rodeo (BoR 2018) which, via a 'methodological' test bed, intends to validate new predictive algorithms of medium range temperature and rainfall forecasts in order to integrate innovation into practice. In general, the goal of the OTB organization is to ensure that 'art to practice' comparisons are carried out in a systematic way, enabling verifiable results that are widely disseminated.

(5) Community integration: At the local level, OTB activities would have direct feedbacks into the regional industry and community via stakeholder engagement and involvement activities, similar to the role of regional ocean planning bodies or coastal ocean observing systems. At the national level, a series of OTBs would explore different aspects of site characterization for the industry. Thus, gathering OTB results via research network level interactions would feed OTB ideas, concepts, and results back into the industry, create pathways for regulatory changes to be developed and vetted, and engage the broader scientific community in research questions that are of interest but beyond the scope of the OTB itself. Additionally, the collective knowledge base would provide the impetus for future innovations and future OTBs to verify them.

\section{OTBs benefits:}

Importantly, a key aspect of OTBs as accelerators of technology transfer would be their ability to rapidly move innovations from proof of concept to accepted practice, improving the pace at which new technologies and processes are accepted and incorporated into this industry or its regulatory framework. This ability hinges on monitoring data collection and analysis through third party review in an open framework, and would advance the permitting process through systematic technology validation. Finally, via the creation of public databases for learning and advancement and the development of a library of technologies and future possibilities, OTBs would contribute to the national network of research and development centers.

\section{Case Study: A New England Shelf Ocean Test Bed}

- Background

- Proposed Design

- Technologies Advanced

- Potential Lessons Learned

\section{Background:}

As a case study on what a focused OTB plan would look like, the potential development of an OTB near the Rhode Island and Massachusetts Wind Energy Areas (WEAs) is presented that would extend an existing observatory offshore to create an area of intensive observation and monitoring and potentially include a long-term reference station. With five federal lease areas located offshore of the states of Rhode Island and Massachusetts (Figure 9), many of which are in various stages of development, nearterm energy infrastructure projects would be directly impacted by the data collection efforts with the OTB.

The Massachusetts and Massachusetts/Rhode Island WEAs have the following characteristics that make the need for developing and testing innovative site characterization methods potentially critical: 


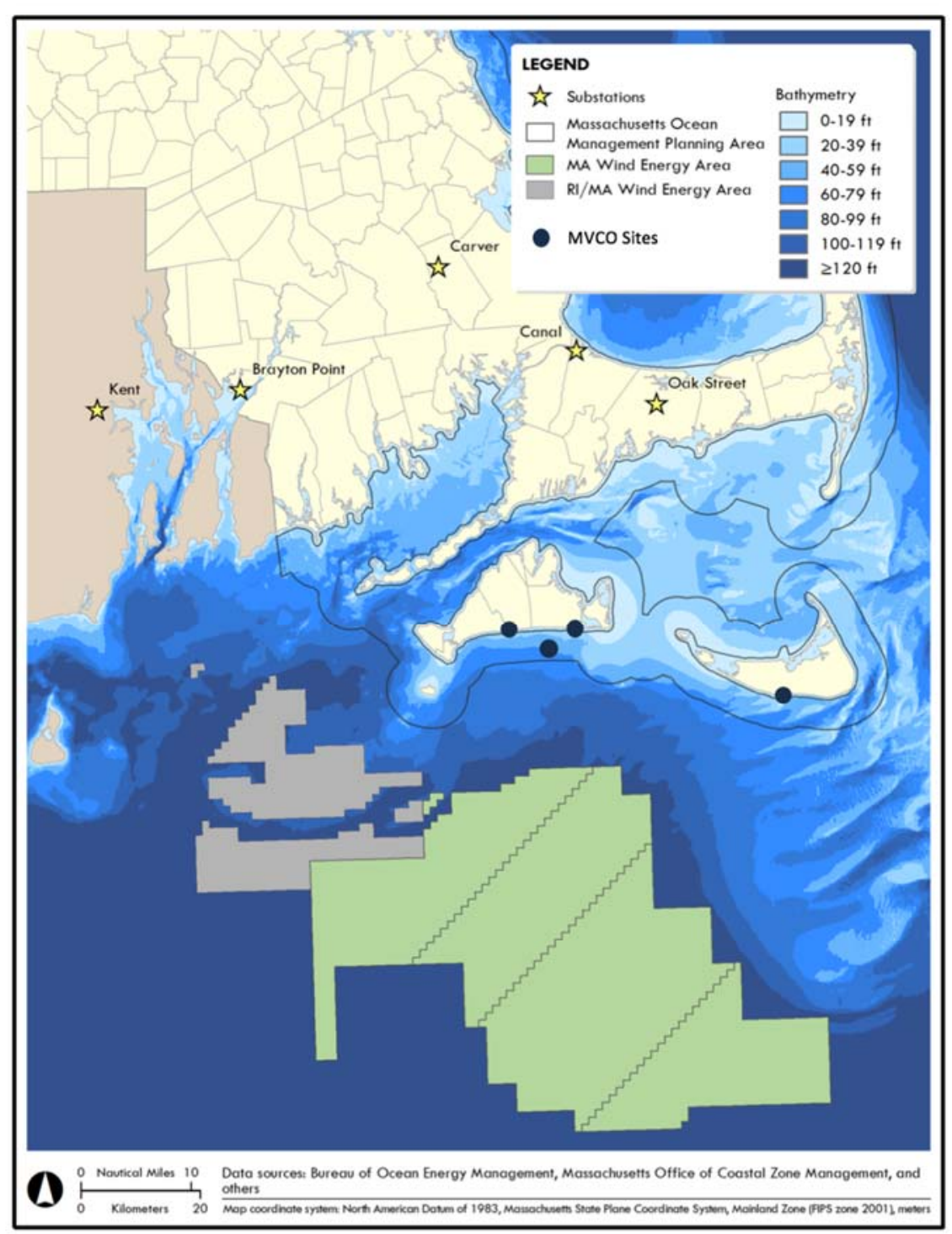

Figure 9: Southeastern

Massachusetts and the New England Shelf showing the MVCO infrastructure locations relative to the RI/MA Wind Energy Areas (WEA). Both the existing grey lease area and the western most green areas are under active development. The first Massachusetts contract for energy production within the areas will be awarded by June 2018. A proposed reference station location is shown in white. Figure credit: Massachusetts Coastal Zone Management (MassCZM).

Geology: The WEAs lie across a shelf area that has been dominated by glaciation for most of the last 100 thousand years. The estimated offshore extent of the last glacial maximum (LGM) encompasses many of the existing lease areas. Boulders are known to be abundant within this and other end-moraine settings that are large enough to present a hazard to wind-farm construction, yet small enough to avoid detection with standard geophysical sampling. Additionally, previous episodes of glaciation have also emplaced fresh water into underlying sediments. There is evidence that this emplaced water, now buoyant relative to seawater, forms localized regions of overpressure in the subsurface that may also present a hazard to wind-farm structure (Siegel et al. 2014).

Marine mammals: Critically endangered North American Right whales, among other species, regularly transit the area making knowledge of and mitigation for critical species an important part of all siterelated efforts. As an example of these issues affecting site activities, construction of the nearby Block Island Farm was limited to narrow temporal windows when species were least likely to be present. 
Atmospheric characteristics: The existence of low-level jets that drive significant shear in the bottom part of the atmosphere can

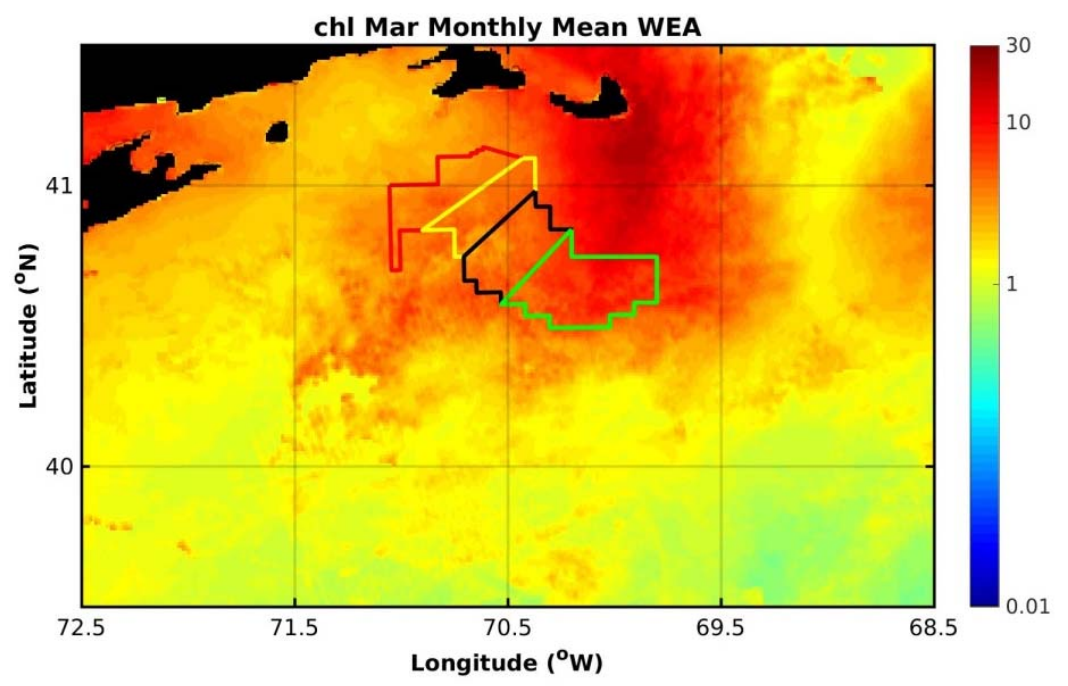

Figure 10: Ocean color image of surface chlorophyll (in $\mathrm{mg} / \mathrm{m}^{3}$ ) acquired with the Visible-Infrared Imaging Spectroradiometer (VIIRS) sensor on Suomi-NPP satellite platform for April 2016. Values of chlorophyll, an indication of biological productivity, are typically high in the Massachusetts wind energy lease areas, outlined on the map.

be present at the sites, most often during stratified summer months.

Additionally, changes in the boundary layer structure are present depending on wind directions being predominantly onshore in summer months and offshore in winter months. However, strong storms can exist in all seasons.

Biologically productive system with commercially valuable fisheries: The Northeastern U.S. continental margin is a highly productive ecosystem (Figure 10), including the wind lease area. Phytoplankton community dynamics can profoundly influence food web and biogeochemical processes. Sustained

temporal observations are needed to provide both a baseline as well as sustained monitoring of seasonal and inter-annual variability in phytoplankton and higher trophic levels in relation to environmental drivers.

The RI-Mass WEAs are also proximate to a number of ongoing basic science research activities and operational data collection initiatives that would benefit any OTB specific data collection or sensor testing activities, including:

- The Ocean Observatories Initiative (OOI)

- The Martha's Vineyard Coastal Observatory (MVCO)

Air Sea Interaction Tower

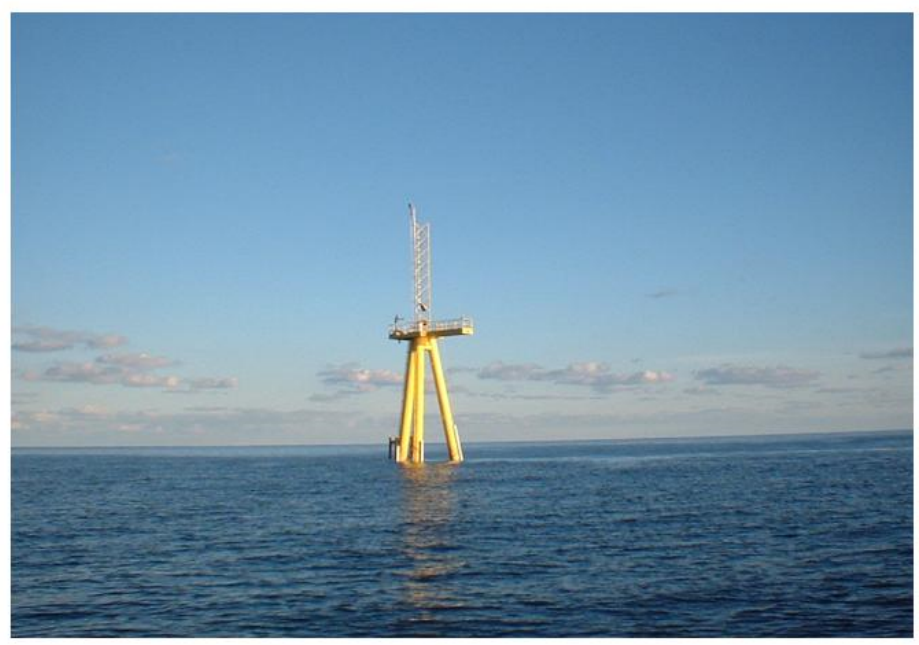

Figure 11: MVCO's existing Air-Sea Interaction Tower (ASIT) located $1.5 \mathrm{Nm}$ offshore of the island of Martha's Vineyard. Facing predominantly onshore winds and open ocean wave - large fetch - conditions during the summer months, the ASIT was built to allow boundary layer studies. Image credit: WHOI. 
- The Northeast Shelf Long Term Ecological Research (NES-LTER) program

- The Mid-Atlantic Regional Association for Coastal Ocean Observation System (MARACOOS)

- The WHOI Center for Marine Robotics

- The WHOI Center for Marine Meteorology and Air-Sea Interactions

Much of the preliminary, desktop-study phase, data aggregation has utilized the 17-year long record of observations from the MVCO's existing Air-Sea Interaction Tower (ASIT) located $1.5 \mathrm{Nm}$ offshore of the island of Martha's Vineyard, 12+ Nm from the WEAs (Figure 11).

\section{Proposed design:}

Coordinated data collection and synthesis efforts within the OTB would advance knowledge of the geologic, oceanic, biologic and atmospheric conditions typical of the WEAs, as well as provide benchmark data sets to serve as a national standard against which innovations are measured and evaluated for their potential to become regulatable, bankable and insurable. Via direct comparisons of state of the art methods and techniques for site characterization and open data repositories for desktop-study analysis of methodological efficacy, these activities would seek to reduce project costs/risks and streamline the permitting process for future OSW efforts in this area as well as nationally.

Leveraging these previous and existing efforts in the region, a potential OTB would focus on collecting data between the existing MVCO infrastructure and the inshore edge of the WEAs. The geological characteristics over the middle part of the shelf are thought to be representative of all of the WEAs in the RI-Mass areas. The land-based facilities of the MVCO on Martha's Vineyard and Nantucket would offer staging areas for larger sensing suites and fixed platforms for land-based ground truth observations.

A component of this effort might require the construction of a fixed research platform to support long term atmospheric, oceanic, and ecosystem monitoring, sensor development and technology transfer (e.g. use of AUV docking stations as monitoring stations), and basic science research objectives. Leveraging the Ocean Test Bed data collection efforts reduces or eliminates the potential cost of the site assessment/design data needed to establish a reference station offshore of the existing MVCO tower at the edge of the existing WEAs. Coupling the OTB activities with the creation of the reference station for long-term atmospheric observations creates a research infrastructure that would be multidisciplinary in nature and attract a diverse group of stakeholders (Table 1).

Table 1: Potential Federal and State Agencies involved in an RI-Mass OTB

\begin{tabular}{|l|l|}
\hline Federal & $\begin{array}{l}\text { Dept. of Energy (NREL/PNNL) } \\
\text { Dept. of Interior (BOEM) } \\
\text { National Science Foundation } \\
\text { Office of Naval Research } \\
\text { National Oceanic and Atmospheric Administration } \\
\text { Massachusetts Clean Energy Center and Coastal Zone Management } \\
\end{array}$ \\
& \begin{tabular}{l} 
Rhode Island Coastal Zone Management \\
\hline
\end{tabular} \\
\hline
\end{tabular}




\section{Technologies Advanced:}

The RI-Mass OTB would focus on advancing the sensing of protected marine species via passive acoustic monitoring; improved mapping of essential fish habit and baseline surveys of ecosystem monitoring; cost-effective geophysical surveys and advanced sub-meter, sub-bottom sensing methods; and the effective evaluation of new Metocean sensors and remote sensing techniques. Initial data collection efforts would seek to resolve the characteristics (Appendix $\mathrm{H}$ ) of an area adjacent to and representative of the WEAs. Combined, these data collection efforts would provide benchmark data sets against which innovations are measured and evaluated for their potential to reduce project costs and risks, update industry standards, develop effective permitting regulations, and monitor long term impacts. The potential lessons learned within this area and its benchmarking activities would be applied both in other potential areas as well as throughout the growing industry via robust stakeholder interactions.

\section{Conclusions and Suggested Course of Action}

The concept of Ocean Test Beds as research and development infrastructure are conceived as part of a network of large-scale national testing facilities, laboratories, and platforms that together are capable of observing, modeling, and monitoring the resource, design criteria, and the environmental impacts of offshore wind energy installations. An ocean test bed, or a suite of regional facilities is needed to move existing or future state of the art methods in site characterization into the state of practice for the industry.

The coordinated data collection and synthesis efforts within Ocean Test Bed(s) would advance knowledge of the continental shelf geologic, oceanic, biologic and atmospheric conditions typical of Wind Energy Areas (WEAs), as well as provide benchmark data sets to serve as a national standard against which innovations are measured and evaluated for their potential to become regulatable, bankable and insurable. Via direct comparisons of State of the Art methods and techniques for site characterization and open data repositories for desktop-study analysis of methodological efficacy, Ocean Test Bed activities would seek to reduce project costs/risks and streamline the permitting process. These both structural and coordinating facilities could include:

1. Directed ocean data collection and synthesis efforts that test new ways of sensing the continental shelf geologic, oceanic, biologic, and atmospheric environments in areas of offshore wind energy development. is:

2. Structured data repository and benchmarking standards for methodological validation and certification.

3. Multi-purpose reference stations supporting research on ocean and atmosphere sensing technologies, autonomous vehicle support, and long-term monitoring.

\section{A network of OTBs is needed:}

Similar to the DOE's investments in large-scale national testing facilities such as the Wind Technology Testing Center and the Drive Train Testing Facility, a network of Ocean Test Beds would advance knowledge of geologic, oceanic, biologic and atmospheric conditions of the U.S. Outer Continental Shelf (OCS) that are relevant not only to the American offshore wind industry and its effective regulation, but contribute substantively to the world-wide growth of this emerging industry as well as basic ocean and atmospheric science research more generally. This fundamental knowledge can serve as the basis for 
developing and testing American innovations in resource characterization. Addressing these research challenges requires an array of actions that a network of Ocean Test Beds within different focal areas of the nation's outer continental shelf resource areas would be able to undertake. Critical to this endeavor, and to the successful result of contributing new methods or information to stakeholders that lowers the cost to rate payers and/or enables better management of our coastal resources, is developing an organizational framework that builds trust among the stakeholders via an open, verifiable process. Developing collaborative structures (i.e. joint public-industry partnerships) for allowing access to project data with appropriate IP or virtual research laboratories are mechanisms by which industry advances can be maximized to the benefit of the rate payer with in an OTB structure.

While network of OTBs is clearly needed to enable efforts in all areas of concern, piloting the concept of an OTB in one such area would allow: the operational framework to be secured in preparation for the continued growth of the industry, the transfer of technological and methodological idea, and the potential stakeholder relations built; providing a roadmap for how this could be done in other areas. We anticipate that the OTBs as developed research infrastructure would have a life span of 20 years, based on the design life of potential structures and the components of existing oceanic monitoring systems that are being utilized now. However, it should be noted that the very nature of the test bed, i.e. what topics or subjects are of interest, would vary based both on the proximate needs and the maturation of the industry it was designed to support.

A case study detailing the needs and potential contributions of an OTB proximate to the RI/MA WEA's was given here, however other physical areas exist within the U.S. OCS in which OTB activities would help answer key outstanding questions that would advance the industry in those areas. OTB activities along the Maryland to New York corridor of the Mid-Atlantic Bight would allow more focused research on the role of diurnal sea-breeze, large scale storm forces on structure and turbine reliability, as well as the sub-bottom composition of the WEA's in the region. Efforts adjacent to the Virginia 2-turbine test site could allow efforts to examine wake effects from installed turbines in near-shore areas. And finally, OTB activities that enable research on deep water wind facilities such as floating turbine structures, moorings, etc. along the U.S. west coast or in the deeper basins of Coastal Maine would help lower the potential costs of these installations in future lease areas.

To conclude, the creation of Ocean Test beds would help provide answers to many of the pressing challenges associated with the growing offshore wind energy industry in the U.S. Regardless of the pathway chosen, work on the sub-topics described above would reap dividends to all ocean stakeholders. The need for progress crosses multiple aspects of the system: finance/project value (wind resource); design (external conditions); and siting/ecological assessment (permitting, impact mitigation). Entraining the research community to understand industry needs and develop systematic research methods via coordinated ocean test beds that can integrate innovation into practice is a tangible path forward. In industries such as ocean energy, where the upfront capital expense of development and the cost of operation and maintenance represents the largest cost factor, the application of technological innovations coming from the ocean research community has the potential to turn projects that are unfeasible or marginally feasible into feasible and profitable projects. In the end, this will lower the risk and costs on the ratepayers. 


\section{Acknowledgments:}

The authors would like to thank Mark Baumgartner, Heidi Sosik, Scott Gallager, Aran Mooney, Laela Sayigh, Kevin D. E. Stokesbury, Dan Lizarralde, and Jim Edson for contributing appendices to this document in their areas of expertise. Fara Courtney and Dan Lizarralde contributed text, ideas, and feedback on the various drafts of the white paper text. AK acknowledges internal support from the Woods Hole Oceanographic Institution via the Houghton Foundation Award.

\section{References:}

Anderson, D.M., Cembella, A.D. and Hallegraeff, G.M., 2012. Progress in understanding harmful algal blooms: paradigm shifts and new technologies for research, monitoring, and management. Annual review of marine science, 4, pp.143-176.

AWS-Truepower, 2015. Metocean Data Needs Assessment for U.S. Offshore Wind Energy AWSTruepower, Prepared under US Department of Energy, Contract DE-EE0005372. http://nassites.org/dels/studies/atlantic-offshore-renewable-energy-development-and-fisheries/

BOEM, 2015. 'Best Practices' in Offshore Wind Energy Lease Activities, 30 CFR Section 585 https://www.boem.gov/uploadedFiles/30_CFR_585.pdf

BoR, 2018, U.S. Bureau of Reclamation's Sub-Seasonal Climate Forecast Rodeo, https://www.usbr.gov/research/challenges/forecastrodeo.html. Accessed on April 4, 2018.

BSH, 2003. Standard for Geotechnical Site and Route Surveys: Minimum Requirements for the Foundation of Offshore Wind Turbines. Germany: Federal Maritime and Hydrographic Agency. (http://www.bsh.de/en/Marine_uses/Industry/Wind_farms/Standard_for_Geotechnical_Site_and_Rout e_Surveys.pdf)

BSH, 2008. Ground Investigations of Offshore Wind Farms. BSH No. 7004. Germany: Federal Maritime and Hydrographic Agency.

BSH, 2011. Offshore wind farms Measuring instruction for underwater sound monitoring, Current approach with annotations Application instructions, http://www.bsh.de/en/Products/Books/Standard/7003eng.pdf

BSH, 2013. Standard: Investigation of the Impacts of Offshore Wind Turbines on the Marine Environment (StUK4) Bundesamt fur Seeschifffahrt und Hydrographie Hamburg und Rostock 2013 BSH-Nr. 7003, http://www.bsh.de/en/Products/Books/Standard/7003eng.pdf

Baumgartner, M.F. and Mussoline, S.E., 2011. Carbon Trust (2013) Offshore Wind Accelerator roadmap for the commercial acceptance of floating LIDAR technology, Carbon Trust, CTC819 Version 1.0, Nov 21, 2013.

Carbon Trust, 2018. Bird Collision Avoidance Study Efforts, https://www.carbontrust.com/offshorewind/orjip/birds/ accessed on Jan. 21,2018. 
Carbon Trust, 2015. Cable Burial Risk Assessment Methodology: Guidance for the Preparation of Cable Burial Depth of Lowering Specification CTC835, February 2015

https://www.carbontrust.com/media/671503/cable-burial-risk-assessment-guidance.pdf

DFFV, 2015. Danish Research Consortium for Wind Energy Wind energy research strategy 2016-2020. DTU Department of Wind Energy, Frederiksborgvej 399, 4000 Roskilde

DOE, 2015, Wind Vision: A New Era for Wind Power in the United States. U.S. Department of Energy (DOE) Office of Energy Efficiency and Renewable Energy. Washington, D.C. (US). DOE/GO-102015-4557. http://www.energy.gov/sites/prod/files/WindVision_Report_final.pdf

DOE-DOI, 2016. A National Offshore Wind Strategy: Creating an Offshore Wind Energy Industry in the United States. The Department of Energy [DOE] Washington D.C. (US), and U.S. Department of the Interior (DOI), Washington D.C. (US). http://energy.gov/sites/prod/files/2013/12/f5/ national_offshore_wind_strategy.pdf

Ecology and Environment, 2014. Development of Mitigation Measures to Address Potential Use Conflicts between Commercial Wind Energy Lessees/Grantees and Commercial Fishermen on the Atlantic Outer Continental Shelf Report on Best Management Practices and Mitigation Measures. A final report for the U.S. Department of the Interior, Bureau of Ocean Energy Management, Office of Renewal Energy Programs, Herndon, VA. OCS Study BOEM 2014-654. 98 pp.

EERI,1995. Assessment of Earthquake Engineering Research and Testing Capabilities in the United States by the Earthquake Engineering Research Institute Committee on Experimental Research, under contract to NSF-NIST, September 1995.

ESRL, 2013, The Wind Forecast System Improvement Project: Final Technical Report (2013), U.S. National Ocean and Atmospheric Administration (NOAA) Earth Systems Research Laboratory (ESRL).

Freedman, J.M., Filippelli, M.V.; Bailey, B.H., 2010, Comparison of Environmental Conditions Between Offshore Sites in Europe and the United States. AWEA Offshore Wind Power Conference. Atlantic City, NJ. 5-7 October 2010.

Gallager, S.M., Singh, H., Tiwari, S., Howland, J., Rago, P., Overholtz, W., Taylor, R. and Vine, N., 2005. High resolution underwater imaging and image processing for identifying essential fish habitat. In Report of the National Marine Fisheries Service Workshop on Underwater Video Analysis (p. 50) http://155.206.14.35/st7/advanced_sampling/NOAA_Technical_Memorandum_SPO_68.pdf\#page=58

Gleason, M., McCreary, S., Miller-Henson, M., Ugoretz, J., Fox, E., Merrifield, M., McClintock, W., Serpa, P. and Hoffman, K., 2010. Science-based and stakeholder-driven marine protected area network planning: a successful case study from north central California. Ocean \& Coastal Management, 53(2), pp.52-68, https://doi.org/10.1016/j.ocecoaman.2009.12.001

Goulette, G.S., Hawkes, J.P., Kocik, J.F., Manning, J.P., Music, P.A., Wallinga, J.P. and Zydlewski, G.B., 2014. Opportunistic acoustic telemetry platforms: benefits of collaboration in the Gulf of Maine. Fisheries, 39(10), pp.441-450, https://doi.org/10.1080/03632415.2014.943740 
Grilli, A.R., Lado, T., and Spaulding, M., 2012, A protocol to include ecosystem services in a wind farm cost model. J. Environmental Eng. 139(2), 176- 186, https://doi.org/10.1061/(ASCE)EE.19437870.0000599

Grilli, A.R. and Shumchenia, E.J. 2015, Toward wind farm monitoring optimization: assessment of ecological zones from marine landscapes using machine learning algorithms. Hydrobiologia, 756(1), 117137, doi:10.1007/s10750-014-2139-3

James, E. P., Benjamin, S.G. and Marquis, M., 2018. Offshore wind speed estimates from a highresolution rapidly updating numerical weather prediction model forecast dataset. Wind Energy, n/a-n/a, https://doi.org/10.1002/we.2161

Kirkpatrick, A.J., S. Benjamin, G.S. DePiper, T. Murphy, S. Steinback, and C. Demarest. 2017. Volume IReport Narrative; Volume II-Appendices. U.S Dept. of the Interior, Bureau of Ocean Energy Management, Atlantic OCS Region, Washington, D.C. OCS Study BOEM 2017-012. 150 pp.,

Lin, F.-C., Li, D., Clayton, R.W., and Hollis, D., 2013. High-resolution 3D shallow crustal structure in Long Beach, California: Application of ambient noise tomography on a dense seismic array, Geophysics, 78(4), Q45-Q56 https://doi.org/10.1190/geo2012-0453.1.

MMI Engineering, 2009 Comparative Study of Offshore Wind Turbine Standards.

MMO, 2014. Review of post-consent offshore wind farm monitoring data associated with license conditions. A report produced for the Marine Management Organisation, pp 194. MMO Project No: 1031. ISBN: 978-1-909452-24-4. https://www.gov.uk/government/uploads/system/uploads/attachment_data/file/317787/1031.pdf MRP, 2017. Massachusetts Research Partnership Workshop on Site Characterization, Final Report. March,2017. http://www.whoi.edu/workshop/offshorewind/home

McCann, J. et al. (2011), The Rhode Island Ocean Special Area Management Plan (Ocean SAMP) vol. 1 http://seagrant.gso.uri.edu/oceansamp/

Musial, W.; Ram, B. 2010. Large-Scale Offshore Wind Power in the United States - Assessment of Opportunities and Barriers. NREL/TP-500-40745. Golden, CO: National Renewable Energy Laboratory, https://www.nrel.gov/docs/fy10osti/40745.pdf

Musial, W. 2017 Offshore Wind Standards, AWEA Offshore Wind Technical Advisory Panel (OWTAP) presentation (September 29, 2017 )

NAS 1951, Oceanography 1951, National Academies of Sciences, National Research Council, Pub. 208. 54 pages.

NAS, 2000. 50 Years of Ocean Discovery: National Science Foundation 1950-2000 Ocean Studies Board, National Academies of Sciences, National Research Councilis: ISBN: 0-309-51744-3, 276 pages. 
NAS, 2018. National Academies of Sciences Atlantic Offshore Renewable Energy Development and Fisheries Steering Committee Activities. http://nas-sites.org/dels/studies/atlantic-offshore-renewableenergy-development-and-fisheries/ (Accessed on January 22, 2018.)

Offshore Wind Hub, 2011. Offshore Electrical Cable Burial for Wind Farms: State of the Art, Standards and Guidance \& Acceptable Burial Depths, Separation Distances and Sand Wave Effect. Project No. 671, Contract M10PC00102. Prepared for: Bureau of Ocean Energy Management, Regulation \& Enforcement - Department of the Interior. http://www.offshorewindhub.org/sites/default/files/resources/boemre_11-28-

2011_cableburialguidance_0.pdf

Siegel, J., Lizarralde, D., Dugan, B. and Person, M., 2014. Glacially generated overpressure on the new England continental shelf: Integration of full-waveform inversion and overpressure modeling, J. Geophys. Res 119, 3393-3409, https://doi.org/10.1002/2013JB010278

Sirnivas, S., Musial, W., Bailey, B., and Filippelli, M., 2014. Technical Report: Assessment of Offshore Wind System Design, Safety, and Operation Standards. NREL/TP-5000-60573 January 2014 Contract No. DE-AC36-08G028308 .

Stephenson, R. et al., 2017. Evaluating and implementing social-ecological systems: a comprehensive approach to sustainable fisheries. Submitted, used with permission.

IEA, 2013. Recommended Practice 15: Ground-Based Vertically-Profiling Remote Sensing for Wind Resource Assessment, International Energy Agency, Version 1.0, January 2013.

IEC, 2011. Wind turbines - Part 12-1: Power performance measurements of electricity producing wind turbines, Annex L, MT12-1 Working Draft 2. 61400-12-1.

Petruny-Parker, M., A. Malek, M. Long, D. Spencer, F. Mattera, E. Hasbrouck, J. Scotti, K. Gerbino, J. Wilson. 2015. US Dept. of the Interior, Bureau of Ocean Energy Management, Office of Renewable Energy Programs, Herndon, VA. OCS Study BOEM 2015-037. 79 pp.,

Wind Europe 2017, The European Offshore Wind Industry - Key trends and statistics 2016; January 2017, Brussels, Belgium, www.windeurope.org.

EY Report 2015, Offshore Wind in Europe / Walking the tightrope to success; March 2015, London, England.

Yu, P., Kurapov, A.L., Egbert, G.D., Allen, J.S. and Kosro, P.M., 2012. Variational assimilation of HF radar surface currents in a coastal ocean model off Oregon. Ocean Modelling, 49, pp.86-104. 


\section{Appendices:}

Details on potential technology transfer and research topic areas:

A. Monitoring marine mammals during wind farm construction.

Mark Baumgartner, Woods Hole Oceanographic Institution

B. Ecosystem monitoring to understand the effects of OSW installations.

Heidi Sosik, Scott Gallager, Aran Mooney, and Laela Sayigh, Woods Hole Oceanographic Institution

C. Fisheries mitigation research efforts.

Kevin D. E. Stokesbury, University of Massachusetts at Dartmouth

D. Marine atmospheric boundary layer characterization.

James Edson, Woods Hole Oceanographic Institution

E. Advancing geophysical and geotechnical knowledge and sampling of the subbottom environment.

Dan Lizarralde, Woods Hole Oceanographic Institution

F. Potential Ocean Test Bed characterization parameters 


\section{Appendix A: Monitoring Marine Mammals During Wind Farm Construction} Mark Baumgartner, Woods Hole Oceanographic Institution

Wind turbine installation has the potential to cause noise that is physically harmful to marine mammals at close ranges or that can disrupt their behavior at long ranges. There are several mitigation options available that fall into two categories of risk management: (1) preventing the spatial/temporal overlap of marine mammals and construction activity and (2) preventing physical damage or behavioral disruption if marine mammals and construction activity overlap. Options for the latter include bubble curtains or alternative pile driving methods to reduce radiated sound. Options for the former include seasonal or real-time cessation of construction activities when marine mammals are detected nearby. This white paper concerns the use of various monitoring technologies to manage interactions between wind farm construction activities and marine mammals.

Human observers typically conduct marine mammal monitoring by visually detecting the animals at the sea surface where they return to breathe. Visual observations can be conducted from a variety of platforms, including ships, airplanes, shore stations and fixed structures (e.g., oil rigs), and is considered the gold standard for species identification and abundance estimation. Visual detection range depends strongly on the height of the platform, aids to the observer (e.g., hand-held or "big-eye" binoculars), weather/light conditions and the observed species, and can vary from a few hundred meters to a few miles. However, visual observations are limited to daytime and good weather conditions, and are often quite expensive since they involve people and large platforms to accommodate those people.

Passive acoustic monitoring has been used extensively over the past 20 years to monitor the occurrence of marine mammals by listening for the distinctive sounds they make. These sounds are often species specific and can therefore be used for identification. Acoustic detection range depends on the source level (i.e., how loud a call is produced), acoustic propagation conditions, frequency of the call, background noise, and the sensitivity of the receiving system, and can vary from hundreds of meters to tens of miles. In contrast to visual observations, the effectiveness of passive acoustic monitoring is not subject to daylight or weather conditions, but instead can be used to monitor marine mammals continuously for weeks to years. However, it is exceedingly difficult to estimate animal abundance from passive acoustic monitoring, and silent animals cannot be detected. Over the past decade, technology to identify the sounds of marine mammals in near real-time using buoys and long-endurance autonomous underwater vehicles (e.g., gliders) has emerged and is now being used routinely to monitor endangered baleen whales in the U.S. and Canada.

Monitoring marine mammals near construction sites typically relies on human observers placed at the construction site, either on a ship or a fixed platform. The detection range of these observers is relatively small, and may be just adequate to monitor the area in which physical harm from loud noises would occur. However, the area over which behavioral disturbance occurs is much larger than the observer can see (e.g., for baleen whales, this area has a radius of at least several miles). Because of the observer's short detection range, visual monitoring at the construction site alone is inadequate to mitigate the effects of construction noise on marine mammals.

The most effective mitigation strategy will involve a combination of monitoring approaches, including broadscale visual surveys, near real-time passive acoustic monitoring, and construction site visual monitoring. Each of these approaches has limitations, but when used in combination, the effect of 
these limitations on the overall detection process can be minimized. The state-of-the-art in marine mammal monitoring for this application includes (1) aerial surveys with human observers, (2) near realtime passive acoustic monitoring from buoys and gliders, and (3) human observers and infrared camera systems stationed at the construction site. While no observing system can reduce to zero the chance of interaction between marine mammals and construction activity, these systems used together provide the best chance of detecting marine mammals in the vicinity of a construction site.

While aerial surveys have been used for decades and survey methodologies are quite mature, additional testing is required for near real-time passive acoustic monitoring and infrared camera systems, particularly for application to wind farm construction mitigation. Significant work has been done to build prototype systems, and preliminary results suggest that these technologies work very well. Additional details, such as detection range, probability of detection under different conditions, and detection timing relative to construction activities, should be better understood before applying these promising systems to mitigating the effects of construction activities on marine mammals.

Detections from aerial surveys and near real-time passive acoustic monitoring systems should be used as a general indicator of marine mammal presence in the area surrounding a construction site. Acoustic systems that attempt to localize individual animals can be useful in the moment, but only for vocalizing (non-silent) animals and only for a short period of time. Marine mammals are highly mobile, and positions obtained even an hour or two ago will not be good estimates of where the animal is currently located. Reliable and automated acoustic localizations are an area of research that, if desired, will take time to develop.

Finally, phased construction activities will be crucial to the development of effective mitigation strategies. Initially, small construction projects should be associated with intensive research to study the impact of construction activities on marine mammals and the effectiveness of monitoring efforts. Only after mitigation strategies are well developed and impacts to marine mammals are minimized should large-scale wind farm construction begin. 
Appendix B: Ecosystem monitoring to understand the effects of OSW installations

Heidi Sosik, Scott Gallager, Aran Mooney, and Laela Sayigh,

Woods Hole Oceanographic Institution

At the scale envisioned, wind farms will have significant interactions with the marine environment, and marine ecosystems. How these interactions can be managed most effectively such that the goods and services produced by continental shelf ecosystems are sustained alongside planned energy-production activities is an important and challenging question with broad implications. Potential stakeholders include all users of marine ecosystem services, including marine shipping and commerce, energy extraction, commercial fisheries, and recreation.

The northwest Atlantic is particularly renowned for productive fisheries that depend upon a complex food web of planktonic organisms. In these waters-as in coastal waters around the globe-human activities, environmental variability, and decadal-scale change are already intersecting to have diverse effects on the planktonic food web. There is a growing need for fundamental understanding of patterns and causes of variability to provide the basis for sustainable management and mitigation of negative impacts. This will be critical to maximize the net benefits of renewable energy extraction in marine waters.

Marine ecosystems are notoriously challenging to observe and characterize due to factors including their large spatial extent, high degree of spatial and temporal variability, huge dynamic range of important organisms-from microscopic primary producers to elusive deep-diving megafauna, and the typically remote and harsh conditions for sampling. These challenges must be overcome to provide quantitative information on ecosystem state in conjunction with pre- and post-construction and operational phases of OSW development. Emerging technology advances provide some important pathways forward, but they require demonstration in a test bed framework to prove their readiness for specific OSW-related needs.

Advanced mapping of essential fish habitat, high-resolution baseline surveys, and ecosystem monitoring, including assessment of plankton communities, nutrient fields, and trophic pathways are required within an open framework with regulatory feedbacks to minimize potential impacts. While some aspects of this topic area are being actively pursued (i.e. BOEM's current RODEO project to monitor construction activities for biological impacts), more is needed. Two important classes of new observational technologies are optical imaging systems and acoustic monitoring.

\section{Monitoring and Assessment with Optical Imaging}

In recent decades, there has been a dramatic upsurge in availability of instrumentation for optical imaging of marine organisms (Fig. 1) (e.g., Benfield et al. 2007; Olson and Sosik 2007; Sieracki et al. 2009; Gallager et al., 2005; Gallager, 2017a; b). These instruments provide unprecedented capability to characterize spatial and temporal variability in phytoplankton and zooplankton, including gelatinous animals and larvae of nekton. Because they respond quickly to environmental factors and play critical roles in food webs and biogeochemical processes, these organisms can serve as important early indicators of change in marine ecosystems. 

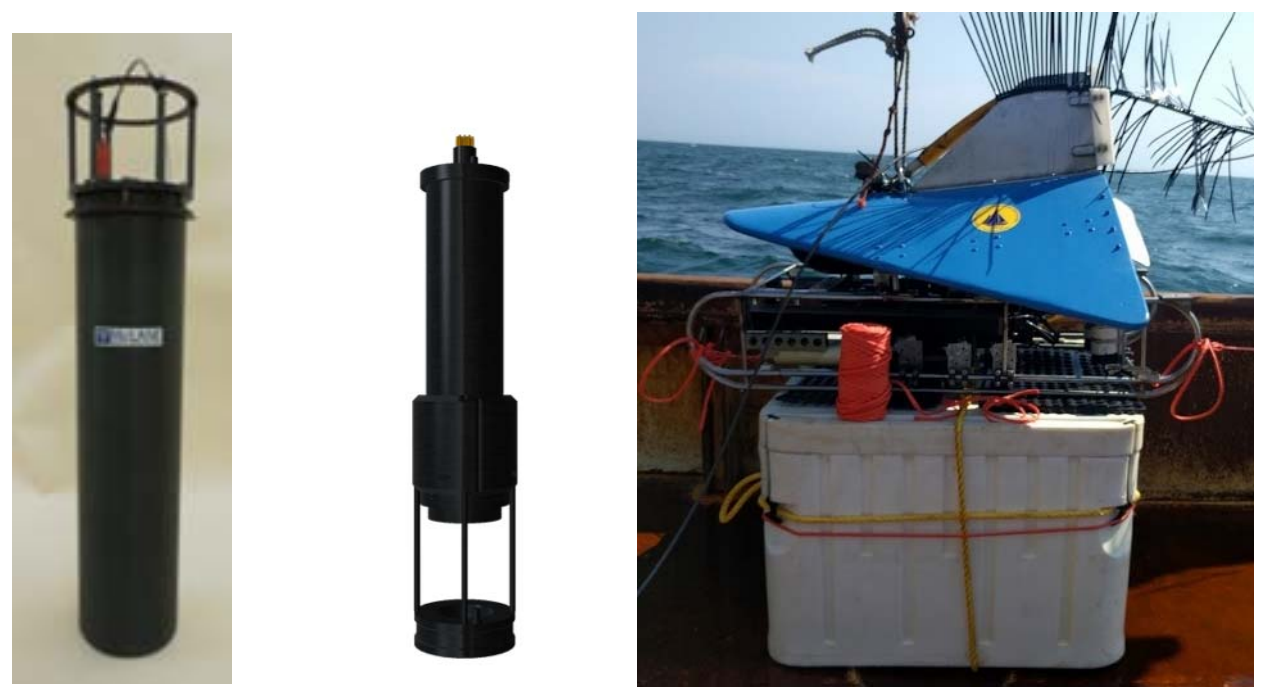

Figure 1. Examples of new technologies for automated in situ microscopic imaging of marine plankton and benthic habitats. Left: Imaging FlowCytobot, optimized for imaging single-celled primary producers (phytoplankton) and protozoa; Middle: CPICS, optimized for imaging secondary producers (zooplankton) and marine aggregates; Right: HabCam benthic stereo-imaging vehicle, optimized for imaqina surveys of benthic environments.

Monitoring plankton for specific impacts, such as might be associated with construction or operational phases of OSW facilities, is confounded by high levels of variability associated with natural fluctuations and cycles (e.g., seasonal, tidal, daily), as well as ongoing effects of climate change and other long-term influences. Untangling short term impacts requires baseline information and long term monitoring processes and standards.

The Martha's Vineyard Coastal Observatory (MVCO) provides examples of how this can be done successfully. This nearshore, cabled observatory facility serves as a prototype that could be replicated at strategic sites further offshore and co-located with OSW installations. Measurements of physical properties of the ocean and atmosphere have been made continuously at MVCO since 2001, and optical instruments making high frequency assessments of plankton have been deployed for over a decade (e.g., Imaging FlowCytobot; Fig. 1). Long records such as these are providing important new knowledge about change at the base of the food web, including advancing spring blooms (Hunter-Cevera et al. 2016) and changes in species composition (Peacock et al. 2014) linked to inter-annual variability in temperature and multi-year warming trends.

These kinds of long-term baselines and associated knowledge about ecological impacts of environmental change must be developed to enable effective impact monitoring in marine ecosystems. Deployment of automated plankton sensors at strategic offshore locations is technologically tractable and highly effective for this problem. 


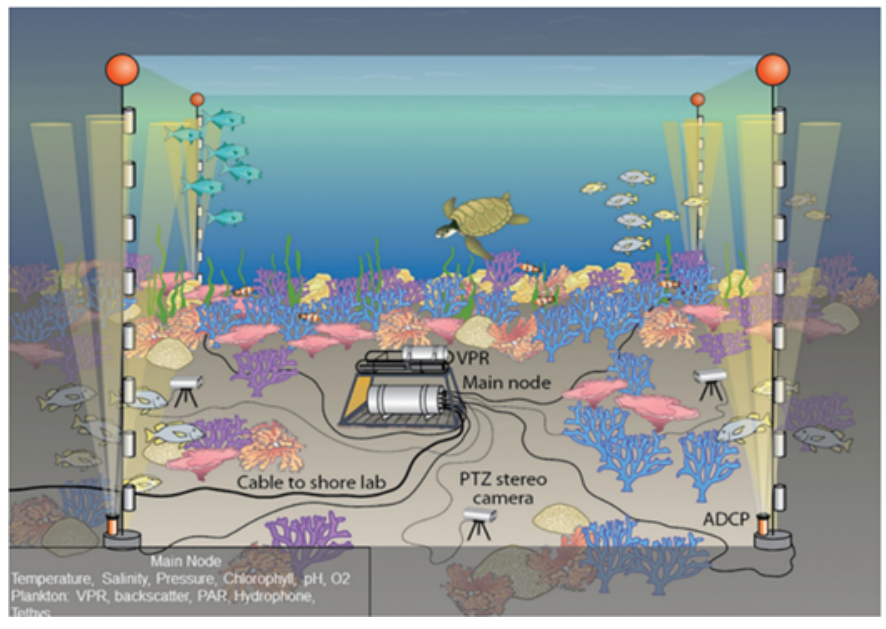

Figure 2. OceanCube observatory deployed at a depth of 20 meters showing four corners defined by thermistor strings and uplooking ADCPS, with a CPICS plankton imaging system in the center.

Imaging of benthic community structure and habitat in relation to substrate type has recently become accessible through an instrument called HabCam (Gallager et al. 2005, Taylor et al., 2008) (Fig. 1). This towed stereo imaging system takes 6 stereo images per second, and combines them into a ribbon-like mosaic in real-time while moving at $7 \mathrm{kts}$, allowing an extensive seafloor area to be covered very quickly. Al-based software is now classifying organisms and substrate as the images are recorded on the ship. This type of instrument is being used by the NOAA Northeast Fisheries Science Center to survey deep sea scallop populations along the Northeast continental shelf and to rapidly characterize seafloor communities and provide habitat information on demersal fish community structure.

The OceanCube Observing systems are relatively inexpensive cabled seafloor observatories that have been installed in coastal systems (depth $20 \mathrm{~m}$ ) around the world (Okinawa, Tokyo, East and West coasts of Panama (Gallager, 2017a). The straightforward and rugged construction and use of a cable provides access to 10 s of sensors and camera systems including the CPICS Continuous Plankton Imaging and Classification System, which provides a stream of phyto- and zooplankton images and classifications in real-time (Gallager, 2017b). The OceanCube Observing system may be deployed by small boat and just a few individuals making it an efficient alternative to costly off-shore observing installations. It is designed to calculate the flux of materials (energy, plankton, carbon, etc.) through its cubic volume providing an instantaneous index of primary and secondary production.

Automated Classification of Plankton

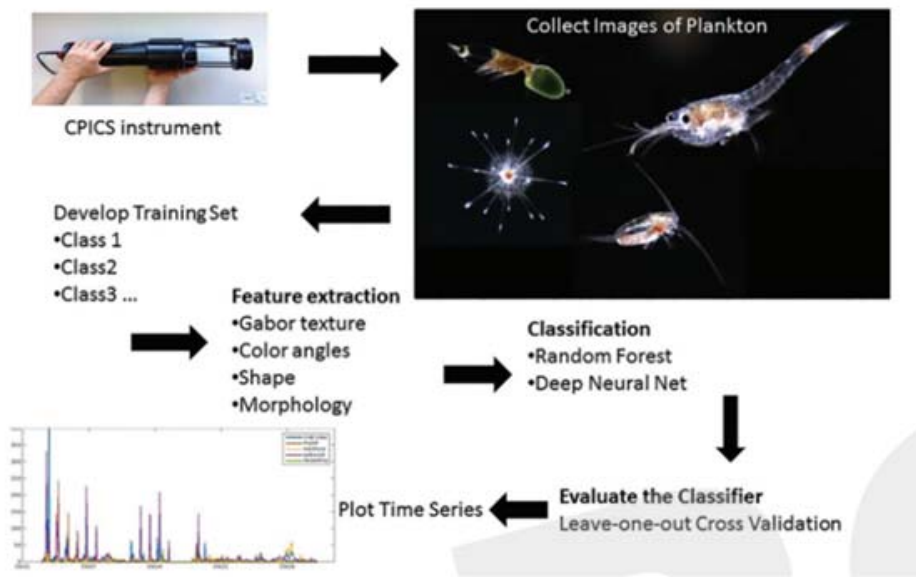

Figure 3. Automated classification of plankton using the CPICS instrument on an OceanCube observing system.

Rapid fluctuations in plankton and benthic community structure as measured by this instrumentation may be used as indicators of ecosystem change: as the variance in population structure (e.g., biodiversity) reaches a maximum threshold, the prediction is a flip towards low biodiversity as the ecosystem re-stabilizes with fewer species (Gallager, 2017b). HabCam, the OceanCube and CPICS are commercially available through CoastalOceanVision.com. 


\section{Monitoring and Assessment with Acoustic Techniques}

Many fishes, mammals and invertebrates make sound. The ambient sound field may be a useful way of gauging biological activity, species presence, diversity and ecosystem health, because many vital behavioral processes are often accompanied by sound production, and a broad range of marine animals produce sound.

These sounds are reflective of a number of vital ecological processes, such as spawning, courtship, feeding, and competition. Quantifying this 'soundscape' is an emerging method to measure biological communities present, their health and condition, and collectively, biodiversity. Trends in soundscape variability have been identified in some marine environments, suggesting that acoustic ambient frequency and temporal qualities may reveal habitat differences and changes to those habitats due to human or other influences.

We envision integrating multiple acoustic receivers, forming a spatial array and allowing coherent processing (beamforming or matched-field processing) to establish the direction of sound sources. These will include soniferous fish such as cod and haddock, endangered North Atlantic Right Whales (NARW), invertebrates and other protected marine mammals within respective study locations. Beyond sound pressure (which is relatively easily detected and monitored), this array and a 3D accelerometer unit will also enable estimation of acoustic particle motion (velocity and acceleration) which can be substantial at low frequencies, is likely generated by OSW devices and is the primary acoustic modality for fish and marine invertebrates. For those species for which we have acoustic calls parameterized (i.e., grey seals, and cetaceans including North Atlantic right whales, humpback whales, fin whales, various dolphins and harbor porpoise), we will be able to document seasonal and diel trends and compare to OSW activity.

We will assess biodiversity diversity following new measurements developed for coral reef soundscapes, such as the median difference in daily max and min values (Kaplan et al. 2015) and a fish-sound detector/classifier (Kaplan et al. 2014). These measures seek to statistically quantify soundscape variability relative to the presence of OSW and changes in overall biodiversity between experimental and control areas. Acoustic diversity metrics are novel, but our group is well prepared to develop the analytical framework for their analyses and their use as an index of acoustic impact of OSW on the marine environment.

\section{References:}

Benfield, M. C., Grosjean, P., Culverhouse, P.F., Irigoien, X., Sieracki, M.E., Lopez-Urratia, A., Dam, H.G., Hu, Q., Davis, C.S., Hansen, A., Pilskaln, C.H., Riseman, E.M., Schultz, H., Utgoff, P.E., and Gorsky, G. 2007. RAPID Research on automated plankton identification. Oceanography 20: 172-187, https://doi.org/10.5670/oceanog.2007.63

Gallager, S.M., Singh, H., Tiwari, S., Howland, J., Rago, P., Overholtz, W., Taylor, R. and Vine, N., 2005. High resolution underwater imaging and image processing for identifying essential fish habitat. In Report of the National Marine Fisheries Service Workshop on Underwater Video Analysis (p. 50), https://pdfs.semanticscholar.org/5aa9/ec1bfda23e339f57ea238a75c73d5b3b1045.pdf 
Gallager, S.M., 2017a. The OceanCubes project: Low-cost cabled observatories for long-term, high frequency monitoring of coastal oceans. September, 2017, Ocean News and Technology.

Gallager, S.M., 2017b. The Continuous Plankton Imaging and Classification System (CPICS) is providing automated measurements of plankton biodiversity on long-term observing systems. June, 2017, Ocean News and Technology.

Hunter-Cevera, K. R., Neubert, M.G., Olson, R.J., Solow, A., Shalapyonok, A., and. Sosik, H.M., 2016. Physiological and ecological drivers of early spring blooms of a coastal picophytoplankter. Science 354 : 326-329. doi:10.1126/science.aaf8536

Kaplan, M. B., Mooney, T. A., Partan, J., and Solow, A. R., 2015. Coral reef species assemblages are associated with ambient soundscapes. Marine Ecology Progress Series, 533, 93-107.

https://doi.org/10.3354/meps11382

Kaplan, M. B., Mooney, T.A., and Partan, J., 2014. Automatic detection of tropical fish calls recorded on moored acoustic recording platforms. Journal of the Acoustical Society of America 136:2153-2153, https://doi.org/10.1121/1.4899784

Olson, R. J., and Sosik, H.M.. 2007. A submersible imaging-in-flow instrument to analyze nano- and microplankton: Imaging FlowCytobot. Limnology and Oceanography Methods 5: 195-203, https://doi.org/10.4319/lom.2007.5.195

Peacock, E. E., Olson, R.J., and Sosik, H.M., 2014. Parasitic infection of the diatom Guinardia delicatula, a recurrent and ecologically important phenomenon on the New England Shelf. Marine Ecology Progress Serles, 503: 1-10, https://doi.org/10.3354/meps10784

Sieracki, M. E., Benfield, M., Hanson, A., David, C., Pilskaln, C.H., Checkley, D., Sosik, H.M., Ashjian, C., Culverhouse, P., Cowen, R., Lopes, R., Balch, W., and Irigoien, X, 2009. Optical plankton imaging and analysis systems for ocean observation, OceanObs'09. https://abstracts.congrex.com/scripts/jmevent/abstracts/FCXNL-09A02a-1671911-1-cwp4a10.pdf.

Taylor, R., Vine, N., York, A., Lerner, S., Hart, D., Howland, J., Prasad, L., Mayer, L. and Gallager, S., 2008, September. Evolution of a benthic imaging system from a towed camera to an automated habitat characterization system. In OCEANS 2008 (pp. 1-7). IEEE. 


\section{Appendix C: Fisheries Mitigation Research Efforts}

Kevin D. E. Stokesbury, University of Massachusetts at Dartmouth

The development of the windfarm industry off the North Atlantic Coast of the United States has great potential for additional harvest of sustainable energy, but will take up a large amount of space in an already crowded marine environment. Linking the latest sampling techniques and strategies with ecosystem models (oceanographic, population dynamics, ecosystems) will be critical to assess interactions on the scales at which the fisheries and windfarm development interact. Doing so will provide the means to understand the effects of this new industry on the sea and suggest ways to mitigate negative impacts while allowing a continuing supply of sustainable seafood and renewable energy to an increasing hungry world.

Windfarm development will impact the United States North Atlantic seaboard in four primary areas; the sea floor, the water currents, the electromagnetic field, and the acoustic environment. These will affect the marine community and in turn the fisheries ( $\$ 1.75$ billion in landings in 2015 ) that the marine community supports (FUS 2015). How much of an effect and whether it is positive or negative is presently debated but needs to be estimated and measured scientifically as windfarm development moves forward. To do so requires an understanding of the present marine ecosystem and how it is changing over time.

Windfarm development will affect the sea floor primarily by physical alteration; large foundations are put into place to anchor and support the wind turbines and sediment redistribution may occur around these foundations depending on bottom water current. Cables will need to be laid on the sea floor, usually in a trench that may also be covered by some type of protective structure (such as a concrete mesh). The two most valuable fisheries in New England are the sea scallop and the Atlantic lobster (combined worth approximately $\$ 1$ billion annually). The sea scallop is a sedentary species that prefers a sand-gravel substrate to live on. Densities decline with increasingly complex habitat, probably as this habitat provides refuge for the scallops' predators. Lobsters prefer complex habitat and therefore an increase in structure may provide increase habitat. Offshore clams are also a valuable fishery and these animals prefer fine sediment. Many fish species are attracted to complex substrate, which can increase both prey species and predators. The flatfish assemblage requires sand substrates and so do sand lance, which are a key forage fish for most of the groundfish assemblage as well as large marine mammals.

Windfarm development will affect the water column by harvesting energy from the wind (altering its affect on current and wave development) and by creating barriers. The water must flow around, producing eddies causing variations on current and breaking up stratification which will affect temperature distribution in the water column. The missing link in almost all fisheries is the stockrecruitment relationship; where do the recruits come from and how many adults are needed to produce them? Whether the change in current structure and stratification will affect fisheries by interacting in this relationship is unknown. At present, modeling these variables is possible but the design (including spacing) of the windfarm is required.

Coupled with the effect of the windfarms on the water column is the effect on the electromagnetic environment. The vast majority of species supporting fisheries on the Eastern Seaboard of the United States are migratory. They move to different feeding grounds, spawning grounds and nursery areas, and these areas include rivers, estuaries, the nearshore, the continental shelf, the deep ocean and the North Atlantic gyre. Many of these migrations cover vast distances seasonally, for example, river herring (Alewife, Blueback Herring and American Shad), Stripe Bass, Atlantic Sturgeon and Great White sharks all 
migrate up the US coast to the Bay of Fundy in Canada to feed each summer and then return in the fall. In 1984-5, 13,500 American shad were tagged in the Bay of Fundy and rivers from the tip of Florida to Labrador reported the capture of a tagged fish (Dadswell et al., 1987). Where the wind farms are placed may have effects on these migrations and aggregations, competing directly with fisheries that harvest these aggregations; examples include the sea herring, Atlantic mackerel and squid fisheries off New York. How these fish navigate their migration is unknown but one of the prevailing hypotheses is the use of the earth's magnetic field. With the development of windfarms, large amounts of power will be transmitted through cables to the shore, in many cases cutting across part or all of the continental shelf. Power transported through a cable creates an electromagnetic field. Whether this field will be strong enough to alter migration routes, delay or detour the fish or even be sensed by the fish is unknown. Preliminary work has begun on this but a much larger effort is needed.

The acoustic environment will be affected during construction as the foundations are driven into the sea floor with pile drives. Once the windfarm is constructed, the amount of noise a windfarm generates and increased boat traffic to service the platforms is unknown. Some recent studies suggest it is minimal. Several groundfish species use sound to attract spawning mates; examples are Atlantic Cod and Black Seabass.

The abilities of fisheries to operate within or next to a windfarm depends of the type of fishery; most fisheries that tow a gear will have some degree of difficulty or will not be able to operate at all. Fixed gear may be less affected, although navigation in inclement weather may be increasingly difficult. Some fisheries, such as recreational rod and reel, may benefit from the change in fisheries assemblage due to the wind turbine structures.

The scope of spatial management and examination required to determine the affect of the windfarm on fisheries is large and requires a scientific framework. One proposal is the "The Blue Economy Research Framework." This Framework addresses the four pillars of sustainability-ecological, economic, social/cultural and institutional-and is based on two primary sources, the Canadian Fisheries Research Network (DFRN) led by Dr. R. Stephenson (Stephenson et al 2017) developed examine fisheries sustainability and E. Mayr's "This is Biology" (1997), which describes the biological scales of "individual" (growth, energetic, physiology, injury, predation, spatial distribution), "population" (abundance, spatial distribution, age structure, recruitment, fertilization success) and "community" (recovery, resilience, recolonization, equilibrium shift, tropic levels, physical/chemical shifts in habitat). This framework is under development but requires a level of organization and support that is presently only partially funded.

\section{$\underline{\text { References: }}$}

FUS 2015. Fisheries of the United States, 2015. Current Fishery Statistics No. 2015. Silver Spring, MD. 2016, https://www.st.nmfs.noaa.gov/Assets/commercial/fus/fus15/documents/FUS2015.pdf

Dadswell MJ, Melvin GD, Williams PJ, Themelis DE. 1987. Influences of origin, life history, and chance on the Atlantic coast migration of American shad. American Fisheries Society Symposium Series 1:313-330.

Mayr E., 1997. This is Biology: The Science of the Living World, Harvard University Press, Cambridge. 
Stephenson, R. et al., 2017. Evaluating and implementing social-ecological systems: a comprehensive approach to sustainable fisheries. Submitted, used with permission. 


\section{Appendix D: Marine Atmospheric Boundary Layer Characterization} James Edson, Woods Hole Oceanographic Institution

The region of the atmosphere that is in contact with and influenced by the earth's surface is known as the atmospheric boundary layer $(A B L)$. Frictional coupling with the surface drives wind shear and mechanical turbulence, which tends to decay away from the surface. The height at which the turbulence vanishes is often used to define the top of the ABL, particularly under stratified (stable) conditions. Additionally, heating and evaporation at the surface can drive convective motion that generates additional turbulence and mixing under convective (unstable) conditions. The height of the convective $A B L$ is typically defined by a temperature inversion with dry air aloft. The height of the $A B L$ can vary between 10 s of meters in stable conditions to several kilometers in strong convection.

The Marine ABL (MABL) differs from its terrestrial counterpart mainly through its surface boundary conditions due to the malleable ocean surface, which allows for the generation of waves and currents. The flux of momentum and energy out of the MABL and into the ocean has a significant impact on how surface layer turbulence is parameterized near the ocean surface in numerical models. The large heat capacity of the ocean also allows it to store of the sun's energy over the spring and summer months before it is subsequently released in fall and early winter. This has a noticeable impact in coastal regions leading to delayed spring seasons and extended falls. Although ocean waves can reach heights of over 10 meters in extreme winds, the surface roughness elements are predominantly the short gravity capillary wind-waves. These small roughness elements make the ocean remarkably smooth under most wind conditions, which results in lower shear and turbulence compared and generally higher winds than adjacent terrestrial surfaces. These benefits, i.e., lower shear, less turbulence and higher winds, have made offshore wind farms attractive enough to offset their higher costs of construction and maintenance. However, significant questions remain about the structure and characteristics of the MABL and its impact on wind turbines due to, e.g., low-level jets associated with stable conditions, airsea interaction and the generation of surface waves and currents, and sea-spray generation and the corrosive effect of sea salt.

A series of ocean test beds, each with instrumentation designed to provide high resolution measurements of the MABL and the ocean surface are needed to characterize these effects and their potential impacts on turbine operations. New measurements are required for:

- Physical site characterization of the MABL and surrounding sea surface and their impact on the performance of wind turbines.

- Development and calibration of new instrumentation for in situ and remotely sensed measurements of the MABL.

- 3-D characterization of the MABL and underlying sea surface for model improvements and validation. Coupled models would clearly benefit from similar measurements characterizing the ocean mixed layer.

In combination, the ocean test beds would be designed to address all of these requirements.

\section{Physical Site Characterization:}

Fixed towers, such as the Air-Sea Interaction Tower (ASIT) at WHOI's Martha's Vineyard Coastal Observatory (MVCO)( Austin et al. 2001) provides an ideal platform to provide in situ measurements of the velocity, temperature and humidity profiles and the associated fluxes of momentum, heat and 
moisture in the lower 30 meters above the sea surface. Additional floating systems are needed to add spatial context to the observations of fixed assets at locations that span wind energy interest areas.

To understand the role of the physical sites on MABL dynamics, extrapolation of the profiles and fluxes to turbine heights would be accomplished using techniques such as Monin-Obukhov (MO) similarity theory (e.g., Edson and Fairall, 1998; Edson et al. 2007, 2013). For example, the wind profile is predicted to take the form of:

$$
U(z)=U\left(z_{o}\right)+\frac{u_{*}}{\kappa}\left[\ln \left(\frac{z}{z_{o}}\right)-\psi_{m}\left(\frac{z}{L}\right)\right]
$$

where $U(z)$ is the wind speed at height $z, z_{o}$ is the aerodynamic roughness length, $u_{*}$ is a velocity scaling parameter known as the friction velocity, $\kappa$ is von Karmen's constant and $\psi_{m}$ is a function that accounts for stability effects where $L$ is known as the MO length. The MO length represents the height at which the mechanical and buoyant production of turbulence are equal. This expression assumes a "constant" flux layer, which is typically assumed to be valid in the lowest $10 \%$ of the MABL. The profiles generated from this expression and similar ones for temperature and humidity (e.g., Edson et al. 2004) would be compared to the in situ measurements and extrapolated to turbine height.

This expression is expected to fail under a variety of conditions particularly in stratified and/or offshore flows. However, the extrapolated profiles would be used to validate remotely sensed profiles of velocity, temperature and humidity when they are in good agreement with the in situ measurements. The remotely sensed measurements could then be used to investigate the MABL under all conditions in combination with the actual measurements.

Remotely sensed wind profiles could be measured using fixed and/or buoy LIDAR-based sampling, while the temperature and humidity profiles could, ultimately, be measured by a water vapor DIAL (Differential Absorption LiDAR) system. The DIAL is still in the development phase at research institutions such as NCAR (particularly for temperature), but is expected to be one of the innovative instruments to benefit from the test beds. Land-based high frequency (HF) radar systems and satellite remote sensing will be used to provide spatial maps of meso- to regional-scale variability as seen in the ocean surface characteristics and temporal variability in the temporal the in situ measurements. In turn, the in situ measurements will provide ground truth for improved retrievals.

An example of the ocean test bed observations needed at a fixed site are given below:

- Sonic anemometers deployed at 4, 8, 16 and 32 meters to characterize the momentum and buoyancy flux divergence.

- Infrared hygrometers at 8 and 16 meters to directly measure the latent and sensible heat flux at two levels.

- Additional mechanical anemometers (cup/vane or propeller-vane) and RH/T sensors between these heights.

- A pyranometer and pyrgeometer for downwelling solar and IR radiative fluxes.

- An infrared radiometer for sea-surface (skin) temperature and upwelling IR radiative flux.

- A laser altimeter for high frequency wave measurements.

- $\quad$ Fixed LiDARs for velocity profiles if a full height fixed tower is not present.

- A DIAL (Differential Absorption LiDAR) for scalar profiles

- Near subsurface T/S sensors for bulk temperature and salinity.

- A bottom-mounted ADCP for current profiles and directional wave spectra. 
- HF radar maps of surface currents and winds in the surrounding waters.

- Additional surface moorings and land stations would serve to quantify horizontal gradients (e.g., the surface pressure gradient) and near surface variability.

\section{Model Development and Validation:}

Even "high" resolution mesoscale models such as the Weather Research and Forecasting (WRF) model have rather coarse resolution near the ocean surface. For example, there are typically 10 vertical levels below $1 \mathrm{~km}$ in the WRF model and the lowest grid point is located at approximately 50-60 meters (e.g., Lombardo et al. 2017). Anything below that level is parameterized using an expression like the velocity profile given above. The values at this level are also used in parameterizations of the surface fluxes using bulk formulae such as the COARE algorithm (Fairall et al. 1996a, 1996b, 2003; Edson et al. 2013), which assumes that the variables passed to the algorithm are in the surface layer where scaling parameters such as $u_{*}$ are expected to be constant and the semi-logarithmic profile is valid. As discussed above, this assumption is often invalid in coastal regions with offshore or stratified flows. For example, during the CBLAST-LOW experiment at the ASIT (Edson et al, 2007), the MABL height in stratified conditions are often below the 22-m tower, which would make the height of the surface layer at 2.2-m. Therefore, to be useful for this project, the models will need to include higher resolution in the vertical.

Additionally, the use of Large Eddy Simulations (LES) would provide a critical tool for model development and validation (e.g., Skyllingstad and Edson, 2008). The data from well-initialized LES would combat the scarcity of measurements used for comparison with the numerical models. LES can be run with very high resolution to investigate the detailed structure of the MABL. LES is now being used extensively in air-sea interaction studies to investigate wave-effects on boundary layer structure (e.g., Sullivan et al. 2008; Sullivan et al., 2018). Although improvements to LES in stratified flows are still an active area of research, the combination of LES with the proposed measurements will provide good opportunities for the research community to improve these simulations. Ultimately, a regional LES or an LES nested within a mesoscale model may be the best option for site characterization.

\section{$\underline{\text { References: }}$}

Austin, T., Edson, J., McGillis, W., Purcell, M., Petitt, R., McElroy, M., Ware, J., Grant, C., and Hurst, S., 2002. A network-based telemetry architecture developed for the Martha's Vineyard coastal observatory. IEEE Journal of Oceanic Engineering, 27, 228-234, doi: 10.1109/JOE.2002.1002477

Edson, J. B., and Fairall, C.W., 1998. Similarity relationships in the marine atmospheric surface layer for terms in the TKE and scalar variance budgets. Journal of the Atmospheric Sciences, 55, 2311-2328, https://doi.org/10.1175/1520-0469(1998)055<3C2311:SRITMA>2.0.CO;2

Edson, J., Crawford, T., Crescenti, J., Farrar, T., Frew, N., Gerbi, G., Helmis, C., Hristov, T., Khelif, D., Jessup, A., Jonsson, H., Li, M., Mahrt, L., McGillis, W., Plueddemann, A., Shen, L., Skyllingstad, E., Stanton, T., Sullivan, P., Sun., J., Trowbridge, J., Vickers, D., Wang, S., Wang, Q., Weller, R., Wilkin, J., Williams, A.J., Yue, D.K.P., and Zappa., C., 2007. The coupled boundary layers and air-sea transfer experiment in low winds. Bulletin of the American Meteorological Society, pp. 341-356, https://doi.org/10.1175/BAMS-88-3-341 
Edson, J. B., Jampana, V., Weller, R.A., Bigorre, S., Plueddemann, A.J., Fairall, C.W., Miller, S.D., Mahrt, L., Vickers, D., and Hersbach, H., 2013. On the exchange of momentum over the open ocean. Journal of Physical Oceanography, 43, 1589-1610, https://doi.org/10.1175/JPO-D-12-0173.1

Edson, J. B., Zappa, C.J., Ware, J.A., McGillis, W.R., and Hare, J.E., 2004. Scalar flux profile relationships over the open ocean. Journal of Geophysical Research, 109, C08S09, doi:10.1029/2003JC001960

Fairall, C.W., Bradley, E.F., Godfrey, J.S., Edson, J.B., Young, G.S., and Wick, G.A., 1996a. Cool-skin and warm-layer effects on sea surface temperature. Journal of Geophysical Research, 101, 1295-1308, https://doi.org/10.1029/95JC03190

Fairall, C. W., Bradley, E.F., Rogers, D.P., Edson, J.B., and Young, G.S., 1996b. Bulk parameterization of air-sea fluxes for TOGA COARE. Journal of Geophysical Research, 101, 3747-3764, https://doi.org/10.1029/95JC03205

Fairall, C. W., Bradley, E.F., Hare, J.E., Grachev, A.A., and Edson, J.B., 2003. Bulk parameterizations of airsea fluxes: updates and verification for the COARE algorithm. Journal of Climate, 16, 571-591, https://doi.org/10.1175/1520-0442(2003)016\%3C0571:BPOASF\%3E2.0.CO;2

Lombardo, K., Sinsky, E., Edson, J., Whitney, M.M., and Jia, Y., 2017. Sensitivity of offshore surface fluxes and sea breezes to sea temperature spatial distribution. Boundary-Layer Meteorology, published online, http://dx.doi.org/10.1007/s10546-017-0313-7

Skyllingstad, E. D., and Edson, J.B., 2008. Large-eddy simulation of moist convection during a cold-air outbreak over the Gulf Stream. Journal of the Atmospheric Sciences, doi: 10.1175/2008JAS2755

Sullivan, P. P., Edson, J.B., Hristov, T., and McWilliams, J.C., 2008. Large eddy simulations and observations of atmospheric marine boundary layers above non-equilibrium surface waves. Journal of the Atmospheric Sciences, 65, 1225-1245, https://doi.org/10.1175/2007JAS2427.1

Sullivan, P.P., M.L. Banner, R.P. Morison, and W.L. Peirson (2018) 'Turbulent flow over steep steady and unsteady waves under strong wind forcing', Journal of Physical Oceanography, 48, pp. 3-27. 


\section{Appendix E: Advancing Geophysical and Geotechnical Knowledge and Sampling of the Subbottom Environment}

Dan Lizarralde, Woods Hole Oceanographic Institution

BOEM guidelines for offshore wind-turbine site characterization include regional surveys over a development area and focused surveys surrounding an installation site. The regional surveys involve bathymetric and subsurface characterization of a coarse grid where multi-channel seismic (MCS), magnetometer and multi-beam data are acquired. The regional survey is intended to provide geologic context and to identify hazards or sites and features of archaeological or historic importance. The focused surveys involve a tighter grid of similar observations surrounding an installation site and are aimed at identifying subsurface obstructions and providing data to relate any available cuttings from borings to imaged subsurface strata or features. Seismic velocity analysis based on reflection travel times is performed for all MCS data collected and compared to VSP data where available, and geotechnical measurements (e.g. cone penetrometer) are made proximal to the intended installation.

These site-characterization observations are sufficient in many instances, but in other instances different or additional observations may be necessary. The shallow-subsurface geology of the inner U.S. Atlantic continental shelf varies from glacially dominated offshore New England to sand-covered karstic carbonates offshore of the Carolinas and southward. Each of these regions presents distinct subsurface challenges for wind-turbine installation and potentially for long-term stability. For example, Offshore New England, the presence of boulders within glacial till adds risk and cost to installation. The risk is currently mediated through the use of a time-consuming and expensive technology that is effective, but that does not provide much information beyond identification of a likely subsurface hazard. Farther south, the mere presence of subsurface limestone may render a site unsuitable for turbine installation,

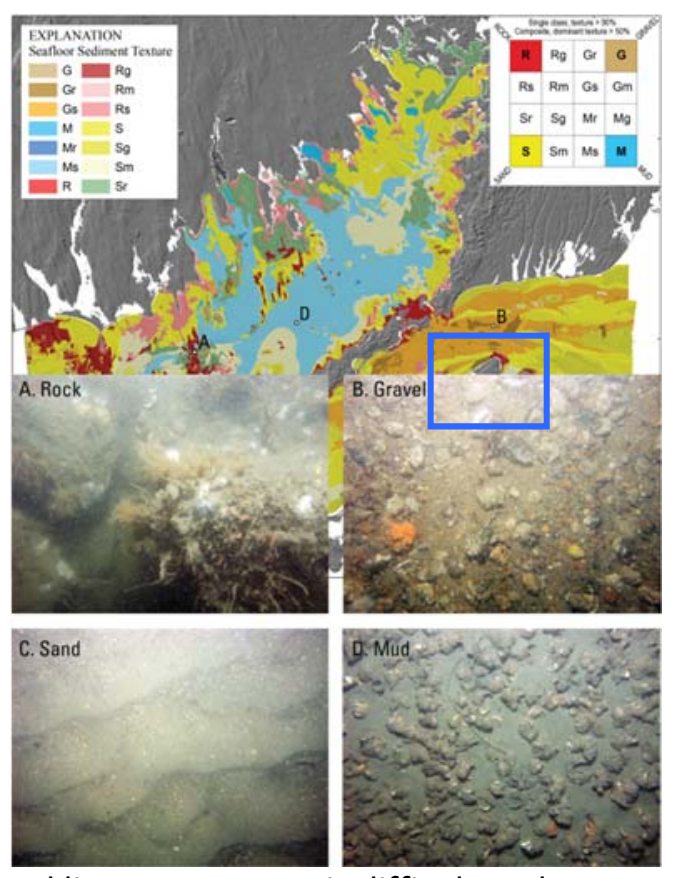

and limestone strata is difficult to detect based on seismic reflection profiling alone. These formations can also have complex karst porosity and associated fluid flow [Evans and Lizarralde, 2003], which could

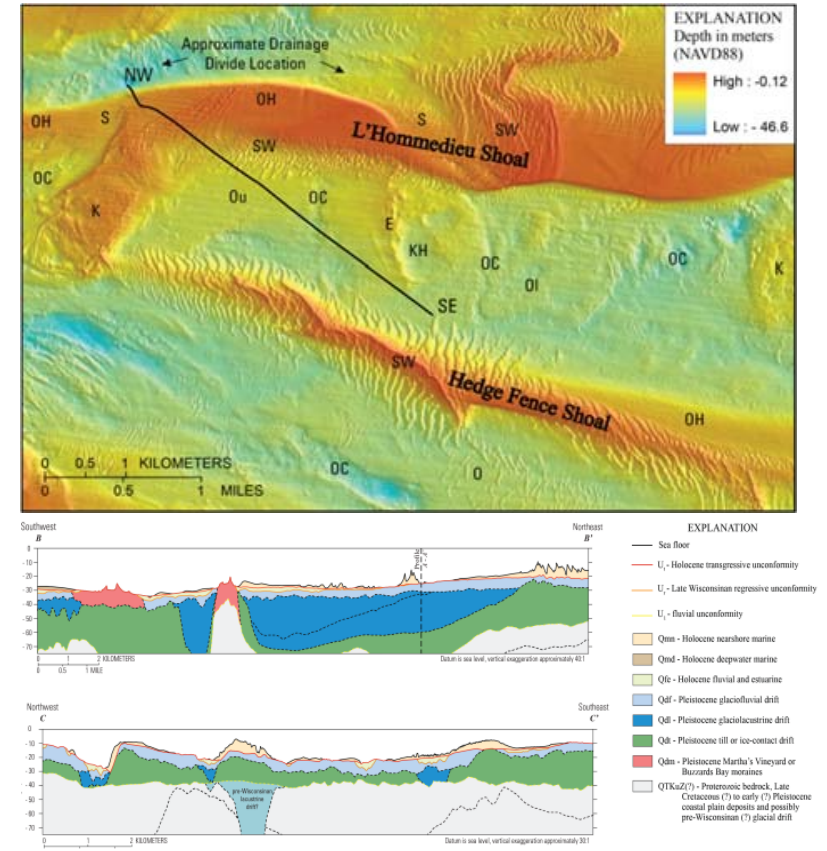

Figure. 1. Example of available USGS geologic and geophysical data, including seafloor maps, bathymetry, coincident interpreted sub-bottom data, and seafloor photographs and samples (from Pendleton, et al., 2012). 
impact the long-term stability of an installation if one is made.

Current practice in site characterization would benefit from established protocols for pre-survey assimilation of existing data, access to new methodologies and survey designs for sub-seafloor imaging, and access to new methodologies for monitoring the evolution of subsurface properties. A vast quantity of high-quality data that characterize the seafloor and shallow subsurface of the Atlantic shelf exists in archives of the U.S. Geological Survey, state geological surveys, and state and local coastal commissions. Most of these data have been contextualized in reports (e.g., Fig. 1). Use of these data benefits contractors, as existing data may meet or exceed the requirements intended to be met by contracted new data acquisition efforts or, at a minimum, help to guide and optimize those new acquisition efforts.

In addition to the suite of observations currently made under BOEM guidelines, there is a range of new methodologies that would benefit wind-turbine site characterization. Three broad categories of particular promise are: ultra-high resolution (UHR) full waveform seismic imaging, which enables 3D structural (reflectivity) and physical property (seismic velocity) imaging at 1-m scale; continuous passive seismic imaging via ambient-noise approaches, which enables monitoring of time-varying seabed physical properties; and electromagnetic imaging, which provides information about the salinity and permeability structure of the subbottom. All of these approaches are mature for imaging at spatial scales of $10 \mathrm{~m}$ or more, but modifications and testing are required to achieve UHR scales.

Meter-scale full-waveform subbottom imaging would mediate risk from obstructions or hazards (e.g. boulder, karst voids) that could complicate installation or impact long-term stability. Figure 2 illustrates the distinction between various types of seismic imaging, considering a mostly 1D stratified subsurface that contains a $1 \mathrm{~m}$ boulder. Vertical-incidence imaging of subsurface impedance (velocity-density product) contrasts, the most common type of imaging, is effective at delineating stratigraphic boundaries, but it does not provide much information on physical properties and, at the frequencies required to image boulders, has difficulty imaging through gas and beneath strong impedance contrasts (Fig. 2b). Tomography based on travel times from arrivals at large source/receiver offsets, or from surface-wave dispersion over similar distances, provide smooth images of background physical properties (Fig. 2c), but detailed structure (i.e. strong contrasts) cannot be imaged without information from the scattered wavefield. The combination of tomography and wavefield imaging, or 'complete' imaging (Fig. 2d), can provide a detailed and complete image of subsurface seismic properties provided that all aspects of the seismic survey are properly designed and executed (e.g. Mora, 1989).
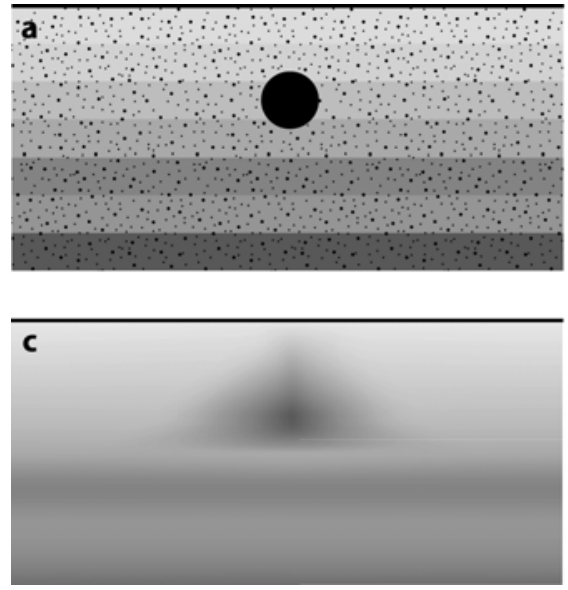

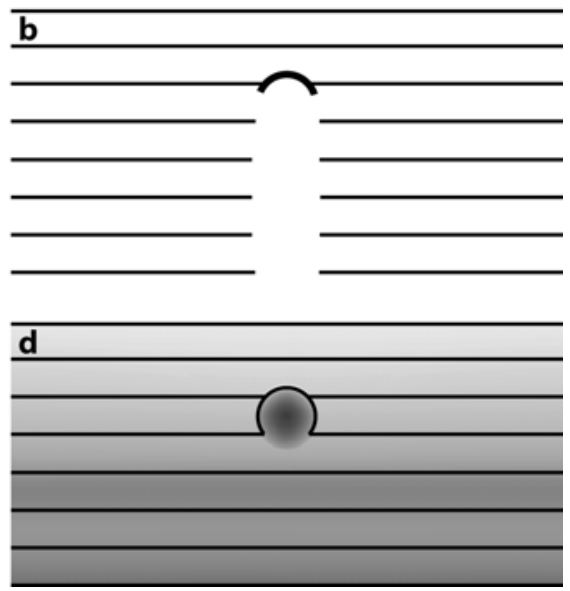


Figure 2. Schematic of seismic imaging. (a) A 2D vertical slice of the subseafloor with a layered structure with velocity (grey shade) generally increasing with depth, small heterogeneities and one large "boulder." (b) Vertical subbottom profiling (e.g. boomer, short streamer MCS, pangeo acoustic corer) images impedance contrasts; though it is often impossible to see below strong impedance contrasts from gas or boulders in sand. (c) Seismic tomography images the background (smooth) velocity field. (d) Combined tomography and wavefield imaging provides both physical property and structural information for features larger than the seismic wavelength when the wavefield is adequately sampled.

Meter-scale seismic imaging requires, at a minimum, seafloor sensors with high positional accuracy. Seafloor sources would also be helpful, and ideally those sources would generate shear waves. While there are no off-the-shelf acquisition kits that we know of for this type of survey, standard solid-state MCS streamers could be arranged on the seafloor to test the approach and sensitivities to positional accuracy. Seafloor sources exist, including a design for the S-wave source used by Ewing et al. (1992) and Collins et al. (1996), and a vibrating source recently developed by Norwegian colleagues (Fig. 3; Vanneste, 2011).

Tomographic methods employing an interferometric cross-correlation approach (e.g. Schuster et al., 2004; Lin et al., 2013), using the ambient noise field as a source, are relatively new but are evolving exceedingly fast. These approaches have two particularly attractive attributes: 1) they use surface waves as primary data and thus have great sensitivity to the shear modulus of the subsurface media, and 2) their intrinsic repeatability enables

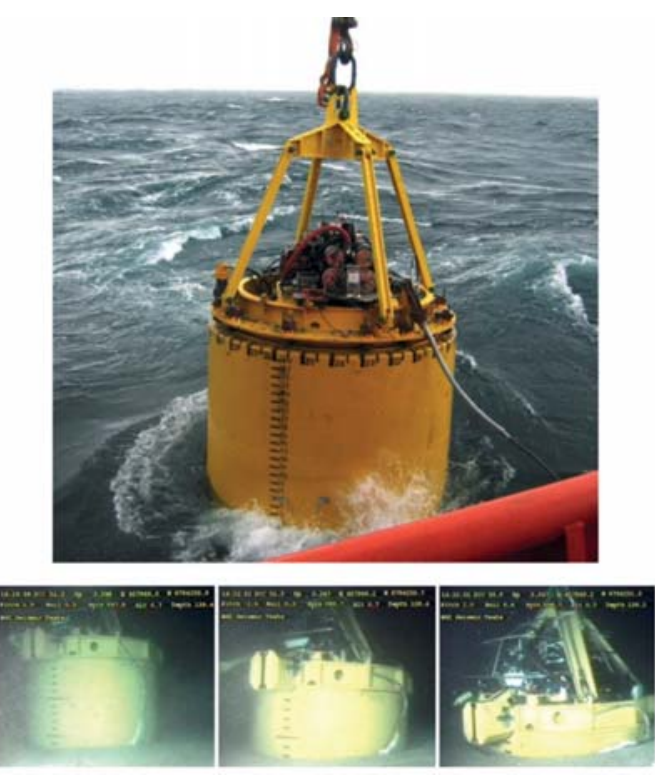

Fig. 3. Norwegian Geotechnical Institute's seabed vibrator source being deployed (top) and snapshots of suction penetration into the seabed (from Vanneste et al., 2011). time-lapse measurements of evolving systems (e.g. Mainsant et al., 2012; Mordret et al., 2014; Hillers et al., 2015). Tomographic images can be obtained from an array of sensors recording the ambient noise field, with the resolution of the images depending primarily on the density of the recording array. For a region with scale relevant to a wind-turbine installation ( $200 \mathrm{~m}$ square to $\sim 50 \mathrm{~m}$ depth), an array of $\sim 12$ 3-component seafloor sensors could record sufficient data to obtain an image in as little as two weeks. A year-long deployment could thus provide a nearly continuous record of the evolving shear properties of the seabed around and beneath a turbine, revealing the seabed's response to loading due to storms, for example, and also identifying any pathological changes in properties. Seafloor seismic 'node' technology is advancing rapidly and also coming down in cost, with a number of off-the-shelf options.

Electro-magnetic (EM) methods provide a means for estimating subsurface salinity and permeability. Recent observations off of New England and New Jersey suggest that significant quantities of freshwater may exist in the subsurface beneath the shelf. In the New England area, there is evidence suggesting that fresh water forced into the subsurface beneath glaciers during lowstands (Siegel et al., 2012; 2014a), and now buoyant relative to seawater, forms localized regions of overpressure in the subsurface (Siegel et al., 2014b) that may present a hazard to large structures. Offshore New Jersey, scientific drilling has confirmed the presence of fresh groundwater within confined units beneath the shelf that may be in hydrologic equilibrium with the terrestrial groundwater system (Lofi et al., 2013). This water is also gravitationally unstable and thus prone to produce seepage sites if confining units are breached. 
Controlled-source EM (CSEM) approaches exist that are ideally tuned to identifying zones of anomalous salinity, porosity, or permeability in the upper $50 \mathrm{~m}$ of the subseafloor (e.g. Evans, 2007). These methodologies, whose development nearly two decades ago was stimulated by national defense interests, are seeing a renaissance as the importance of nutrient and carbon transport via submarine groundwater discharge has gained increasing scientific focus. Various CSEM systems are thus available, and their routine use in wind-turbine site characterization would mitigate risk presented by shallow, low-salinity, overpressured submarine groundwater.

\section{$\underline{\text { References: }}$}

Collins, J. A., Sutton, G.H., and Ewing, J.I., 1996. Shear-wave velocity structure of shallow-water sediments in the East China Sea. Journal of the Acoustical Society of America, 100, 3646-3654, https://doi.org/10.1121/1.417227

Evans, R. L., 2007. Using CSEM techniques to map the shallow section of seafloor: From the coastline to the edges of the continental slope. Geophysics, 72, WA105-WA116, https://doi.org/10.1190/1.2434798

Evans, R.L., and Lizarralde, D., 2003. Geophysical evidence for karst formation associated with offshore groundwater transport: An example from North Carolina, Geochemistry, Geophysics, Geosystems, 4(8), 1069, doi:10.1029/2003GC000510

Ewing, J. Carter, J.A., Sutton, G.H., and Barstow, N., 1992. Shallow water sediment properties derived from high-frequency shear and interface waves. Journal of Geophysical Research, 97, 4739-4762, https://doi.org/10.1029/92JB00180

Hillers, G., Ben-Zion, Y., Campillo, M., and Zigone, D., 2015. Seasonal variations of seismic velocities in the San Jacinto fault area observed with ambient seismic noise. Geophysical Journal International, 202, 920-932, https://doi.org/10.1093/gji/ggv151

Lin, F.-C., Li, D., Clayton, R.W., and Hollis, D., 2013. High-resolution 3D shallow crustal structure in Long Beach, California: Application of ambient noise tomography on a dense seismic array. Geophysics, 78(4), Q45-Q56, 2013, https://doi.org/10.1190/geo2012-0453.1

Lofi, J., Inwood, J., Proust, J.-N., Monteverde, D.H., Loggia, D., Basile, C., Otsuka, H., Hayashi, T., Stadler, S., Mottl, M.J., Fehr, A., and Pezard, P.A., 2013. Fresh-water and salt-water distribution in passive margin sediments: insights from Integrated Ocean Drilling Program Expedition 313 on the New Jersey margin. Geosphere, 9(4), 1009-1024, https://doi.org/10.1130/GES00855.1

Mainsant, G., Larose, E., Brönnimann, C., Jongmans, D., Michoud, C., and Jaboyedoff, M., 2012. Ambient seismic noise monitoring of a clay landslide: Toward failure prediction, Journal of Geophysical Research, 117, F01030, doi:10.1029/2011JF002159

Mora, P., 1989. Iversion= migration + tomography. Geophysics, 54, 1575-1586, https://doi.org/10.1190/1.1442625

Mordret, A., Shapiro, N.M., and Singh, S., 2014. Seismic noise-based time-lapse monitoring of the Valhall overburden, Geophysical Research Letters, 41, 4945-4952, doi:10.1002/2014GL060602

Pendleton, E. A., Baldwin, W.E., Barnhardt, W.A., Ackerman, S.D., Foster, D.S., Andrews, B.D., and. Schwab, W.C., 2012. Shallow geology, seafloor texture, and physiographic zones of the Inner Continental Shelf from Nahant to Northern Cape Cod Bay, Massachusetts, USGS Open-File Report 20121157. 
Schuster, G.T., Yu, J., Sheng, J., and Rickett, J., 2004. Interferometric/daylight seismic imaging. Geophysical Journal International, 157, 838-852, https://doi.org/10.1111/j.1365-246X.2004.02251.x

Siegel, J., Dugan, B., Lizarralde, D., Person, M., DeFoor, W., and Miller, N., 2012. Geophysical evidence of a late Pleistocene glaciation and paleo-ice stream on the Atlantic Continental Shelf offshore Massachusetts, USA, Marine Geology 303-306, 63-74, 2012, https://doi.org/10.1016/j.margeo.2012.01.007

Siegel, J., Person, M., Dugan, B., Cohen, D., Lizarralde, D., and Gable, C., 2014a. Influence of late Pleistocene glaciations on the hydrogeology of the continental shelf offshore Massachusetts, USA, Geochemistry, Geophysics, Geosystems, 15, https://doi.org/10.1002/2014GC005569

Siegel, J., Lizarralde, D., Dugan, B., and Person, M., 2014b. Glacially generated overpressure on the new England continental shelf: Integration of full-waveform inversion and overpressure modeling. Journal of Geophysical Research, 119, 3393-3409, https://doi.org/10.1002/2013JB010278

Vanneste, M., Madshus, C., Socco, V.L., Maraschini, M., Sparrevik, P.M., Westerdahl, H., Duffaut, K., Skomedal, E., and Bjørnara, T.I., 2011. On the use of the Norwegian Geotechnical Institute's prototype seabed-coupled shear wave vibrator for shallow soil characterization - I. Acquisition and processing of multimodal surface waves, Geophysical Journal International, 185, 221-236, https://doi.org/10.1111/j.1365-246X.2011.04961.x 


\section{Appendix F: Potential Ocean Test Bed Characterization Parameters}

With the diverse set of needs facing the industry it is likely that no one single area or single test bed will be representative of all areas or have universal applicability. As formulated a Test Bed could focus on a subset of the characterization parameters given here. However, any potential exercise in data collection should encompass the range of characterization parameters that are generally applicable to ocean development:

Geologic, Geophysical, and Geotechnical information: including bathymetric characteristics, soil, sediment, and rock characterization in the subsurface, and identification of hazards to construction, which can include shipwrecks, debris, and natural features such as sand waves, relict channels, boulders and cobbles, and archaeological and historic artifacts. Following BOEM guidance on site characterization, it is envisioned that the types of remote sensing information that would be collected and synthesized for this set of parameters would include bathymetric data (especially high quality multibeam data), side scan sonar, subbottom profiler, high-resolution seismic streamer, and magnetometer data. Geologic information, including data that may exist from sampling events conducted in and around the Test Bed site, would be incorporated. Geotechnical, including boring data and/or cone penetrometer test (CPT) data that may exist, would also be incorporated.

Physical and Chemical Oceanographic information: including current, wave, tidal, ocean chemistry, salinity, thermal structure information would be synthesized as part of the Site Model. This might include data generated through water sampling events, CTD casts, Acoustic Current Doppler Profiler (ADCP) surveys, and satellite measurements.

Atmospheric and Met-ocean information: including wind and weather information developed from standard met-ocean tower and satellite imagery, as well an evaluation of the efficacy of including atmospheric data gathered from buoy and floating systems that may be relevant to the Test Bed Site.

Biologic information: including data on marine mammals, reptiles, threatened and endangered species, and other marine organisms of concern. Also, included in this parameter are data concerning bird and bat activities within and in the vicinity of the Test Bed area. This may include information concerning migration patterns, use of the area for feeding and/or calving, density of resource, behavior patterns and other parameters that are considered by BOEM to be important in the development of an area. 